Georgia State University

ScholarWorks @ Georgia State University

Spring 5-1-2013

\title{
Comparison of HFNC, Bubble CPAP, and SiPAP on Aerosol Delivery in Neonates: An In-Vitro Study
}

Fatemah S. Sunbul

Georgia State University

Follow this and additional works at: https://scholarworks.gsu.edu/rt_theses

\section{Recommended Citation}

Sunbul, Fatemah S., "Comparison of HFNC, Bubble CPAP, and SiPAP on Aerosol Delivery in Neonates: An In-Vitro Study." Thesis, Georgia State University, 2013.

doi: https://doi.org/10.57709/4134923

This Thesis is brought to you for free and open access by the Department of Respiratory Therapy at ScholarWorks @ Georgia State University. It has been accepted for inclusion in Respiratory Therapy Theses by an authorized administrator of ScholarWorks @ Georgia State University. For more information, please contact scholarworks@gsu.edu. 


\title{
Comparison of HFNC, Bubble CPAP, and SiPAP on Aerosol \\ Delivery in Neonates: An In-Vitro Study
}

\author{
By \\ Fatemah S. Sunbul \\ A Thesis \\ Presented in Partial Fulfillment of Requirements for the \\ Degree of \\ Master of Science \\ In \\ The Division of Respiratory Therapy \\ In \\ Byrdine F. Lewis School of Nursing and Health Professions \\ Georgia State University \\ Atlanta, Georgia
}

2013 


\section{ACCEPTANCE}

This thesis, COMPARISON OF HFNC, BUBBLE CPAP, AND SIPAP ON AEROSOL DELIVERY IN NEONATES: AN IN-VITRO STUDY, by Fatemah S. Sunbul was prepared under the direction of the Master's Thesis Advisory Committee. It is accepted by the committee members in partial fulfillment of the requirements for the degree Master of Science in the BFLSNHP, Georgia State University.

The Master's Thesis Advisory Committee, as representatives of the faculty, certifies that this thesis has met all standards of excellence and scholarship as determined by the faculty.

Arzu Ari, PhD, RRT, PT, CPFT, FAARC

Committee Chair

Robert Harwood, MS, RRT-NPS

Committee Member

Ralph D. Zimmerman, MS, RRT-NPS

Committee Member

Date 


\begin{abstract}
AUTHOR'S STATEMENT
In presenting this thesis as a partial fulfillment of the requirements for the advanced degree from Georgia State University, I agree that the library of Georgia State University shall make it available for inspection and circulation in accordance with its regulations governing materials of this type. I agree that permission to quote, to copy from, or to publish this thesis may be granted by the professor under whose direction it was written, by the BFLSNHP director of graduate studies and research, or by me. Such quoting, copying, or publishing must be solely for scholarly purposes and will not involve potential financial gain. It is understood that any copying from or publication of this thesis which involves potential financial gain will not be allowed without my written permission.
\end{abstract}

Signature of Author 


\title{
NOTICE TO BORROWERS
}

All thesis deposited in the Georgia State University library must be used in accordance with the stipulations prescribed by the author in the preceding statement. The author of this thesis is:

Fatemah S. Sunbul

32 Peachtree St. NW, APT 1204

Atlanta, GA 30303

The director of this thesis is:

\author{
Arzu Ari, PhD, RRT, PT, CPFT, FAARC \\ Associate Professor \\ Division of Respiratory Therapy
}

The Byrdine F. Lewis School of Nursing and Health Professions

Georgia State University

Atlanta, Georgia 30303-3083 
VITA

FATEMAH S. SUNBUL

ADDRESS:

32 Peachtree St. NW, APT 1204

Atlanta, GA 30303

EDUCATION

M.S.

2013

Georgia State University

Byrdine F. Lewis School of Nursing \& Health Professions Atlanta, Georgia

B.S.RT

2009

King Faisal (Dammam) University

College of Applied Medical Sciences

Dammam, Saudi Arabia

PROFESSIONAL EXPERIENCE

April 2009-July 2009 Internship at King Fahad Specialist Hospital in Dammam, Saudi Arabia

December 2008-March 2009 Internship at King Fahad Military Medical Complex in Dhahran, Saudi Arabia

Aug 2008- Nov 2009

Internship at King Fahad University Hospital in Khobar, Saudi Arabia

PROFESSIONAL SOCIETIES AND ORGANIZATIONS

2011-Present

American Association for Respiratory Care

\section{PRESENTATIONS AND PUBLICATIONS}

Comparison of HFNC, Bubble CPAP and SiPAP on Aerosol Delivery in Premature

Babies: An In-Vitro Study, Poster abstract at the meeting of The International Society for Aerosols in Medicine, 2013 Congress in Chapel Hill, NC, USA.

Cystic Fibrosis, A Case Presentation. A continuing respiratory care education presentation for the Respiratory Care Department at Emory University Hospital, Atlanta, GA, USA. 


\begin{abstract}
COMPARISON OF HFNC, BUBBLE CPAP, AND SIPAP ON AEROSOL DELIVERY IN NEONATES: AN IN-VITRO STUDY

by

Fatemah S. Sunbul
\end{abstract}

Background: Aerosol drug delivery via high flow nasal cannula (HFNC), bubble continuous positive airway pressure (CPAP), and synchronized inspiratory positive airway pressure (SiPAP) has not been quantified in spontaneously breathing premature infants. The purpose of this study was to compare HFNC, bubble CPAP, and SiPAP on aerosol delivery in a simulated spontaneously breathing preterm model.

Methods: A breath simulator was set to preterm infant settings $\left(\mathrm{V}_{\mathrm{T}}: 9 \mathrm{ml}, \mathrm{RR}: 50\right.$ bpm and Ti: $0.5 \mathrm{sec}$ ) and connected to the trachea of an anatomical upper airway model of a preterm infant (DiBlasi) via collecting filter distal to the trachea. The HFNC (Fisher \& Paykel), Bubble CPAP (Fisher \& Paykel), and SiPAP (Carefusion) were attached to the model via their proprietary nasal cannula and set to deliver $5 \mathrm{~cm} \mathrm{H}_{2} \mathrm{O}$ pressure. Albuterol sulfate $(2.5 \mathrm{mg} / 0.5 \mathrm{~mL})$ was aerosolized with a mesh nebulizer (Aeroneb Solo) positioned (1) proximal to the patient and (2) prior to the humidifier $(\mathrm{n}=5)$. The drug was eluted from the filter with $0.1 \mathrm{~N} \mathrm{HCl}$ and analyzed via spectrophotometry $(276 \mathrm{~nm})$. Data were analyzed using descriptive statistics, t-tests, and analysis of variance (ANOVA), with $p<0.05$ significant.

Results: At position 1, the trend of lower deposition across devices was not significant; however, in position 2, drug delivery with SiPAP was significantly lower compared to both HFNC ( $p=0.003)$ and bubble CPAP $(p=0.008)$.Placement of the nebulizer prior to the humidifier increased deposition with all devices $(p<0.05)$. 
Conclusion: Aerosol can be delivered via all three devices used in this study; however, delivery efficiency of HFNC is better than the other CPAP devices tested. Device selection and nebulizer position impacted aerosol delivery in this simulated model of a spontaneously breathing preterm infant. 



\section{ACKNOWLEDGMENTS}

First and above of all, I thank God for guiding me, giving me health and power, and making this and everything else possible in my life.

It is my honor to acknowledge those who directed me in the right path and made this thesis possible: Dr. Arzu Ari and Professor Robert Harwood. I am grateful for their guidance, assistance, support, and help. I thank them for their invaluable advice and encouragement and for having the patience to read and edit my thesis chapters over and over. Special thanks to Dr. Ari for devoting her time, knowledge, and research experience in helping me; for her passion and precision in improving my own research experience; and for her patience, continued advice, and help in better understanding the topic and research. Professor Harwood, I offer you special thanks for being there all the time, for your valuable input in directing me to understand and develop this topic, for the endless advice, encouragement, and recommendations. My deepest gratitude goes out to both of these mentors, without whom this thesis would not have been successful.

I also would like to thank Professor Chip Zimmerman for serving on my committee, for his input that first directed me to think in this topic, and for his understanding, assistance and being there whenever I have a question. Special thanks to Dr. Jim Fink for his invaluable input and help while conducting the study, and for his commitment to this thesis. I offer Ms. Meryl Sheard special thanks for her help in my thesis drawings and her assistance in ordering the supplies needed for this thesis.

I thank Dr. Kristin Straiter, product manager at Fisher \& Paykel Healthcare, Inc., for her company's donation of bubble CPAP systems, and Ms. Lorelee Goehle, a senior product manager from CareFusion, for letting us borrow their SiPAP device. 
I would also like to thank the entire faculty and staff of the respiratory care department at Georgia State University, first for allowing me to use their lab and supplies to complete this thesis, and most of all for teaching me how to be a researcher and a better thinker. I enjoyed learning from each one of you. Thank you.

I offer my deepest gratitude to my beloved family for their understanding and endless love. To my husband, Ahmed Alinsaif, thank you for your love and motivation, for being patience and dedicating your time, all the time, during this extremely busy period in our lives; thanks for your never-ending support for my own motivation to complete my Master's degree. Thank you for the reassurance and faith you have in me and for believing in me even when I did not believe in myself. Thank you for being in my life. Thank you to my sons, Hassan and Hussein, for their ambitious love and just for being wonderful sons. Thank you to my supportive and wonderful parents who taught me and have shown me that anything is possible. Thanks to my father who inspired me and still inspires me through his work to reach for my dreams. I have a strong desire to be like him—a smart, successful, and loving mentor. I thank my mother, who dedicated all her time to caring and being there for us. I cannot think of enough words to thank you. I am proud of you and want to make you both proud of me.

I also thank the rest of my family and friends for their unlimited care, love, patience, encouragement, and confidence.

Personal thanks to all of those who contributed in any way and supported me throughout these last two years...

Fatemah Sunbul

April, 2013 
TABLE OF CONTENTS

Page No.

List of Tables .................................................................................................. vii

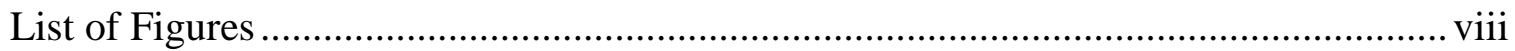

List of Abbreviations ..................................................................................... ix

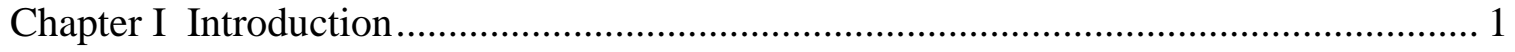

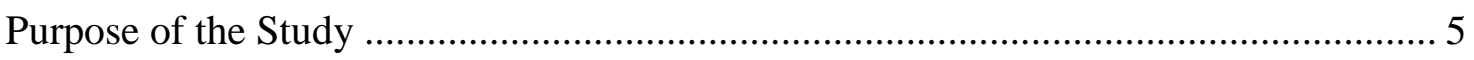

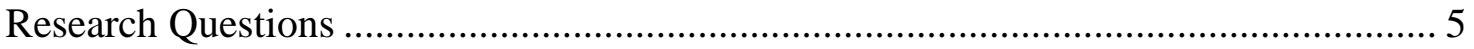

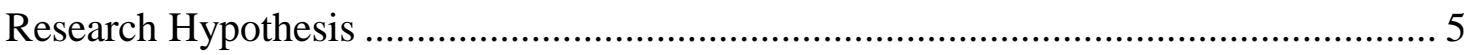

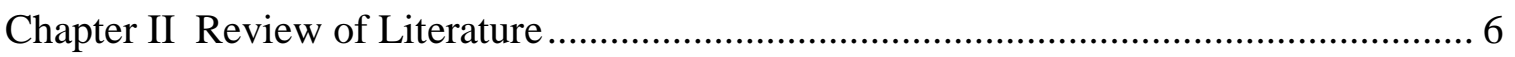

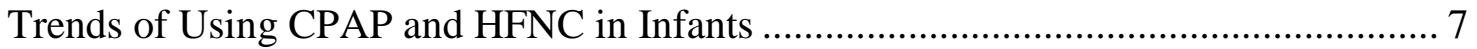

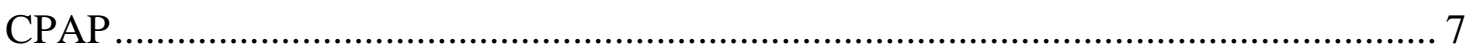

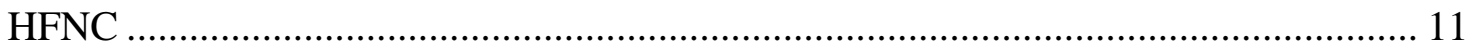

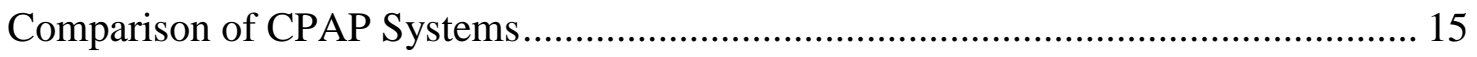

V-NCPAP Versus B-NCPAP .......................................................................... 15

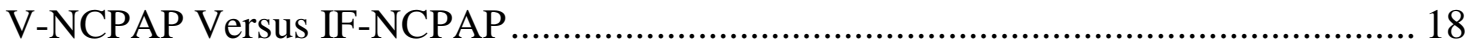

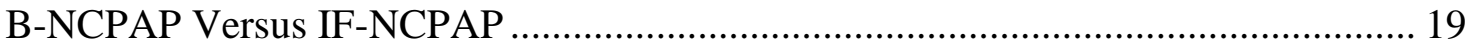

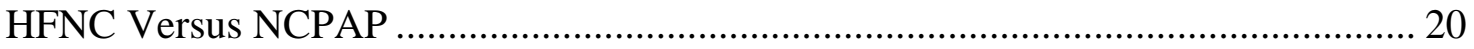

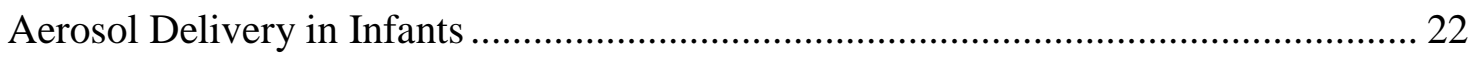

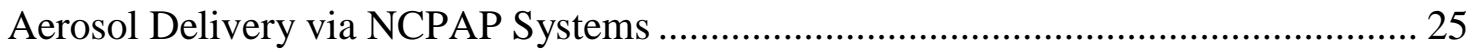

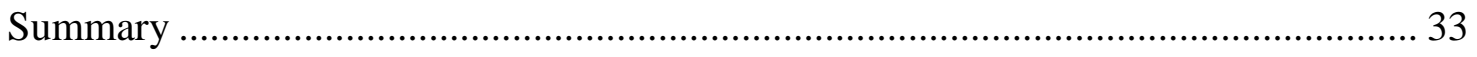




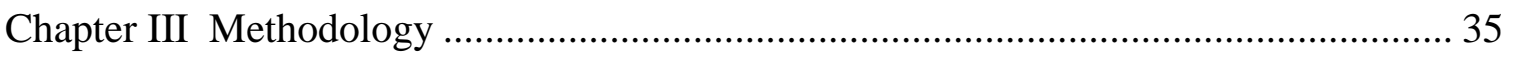

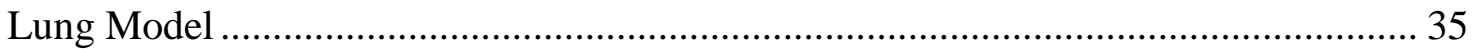

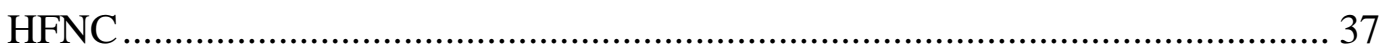

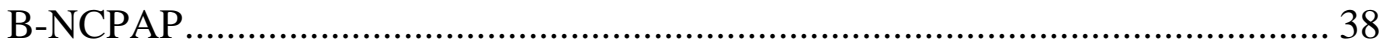

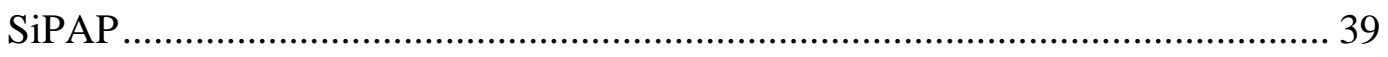

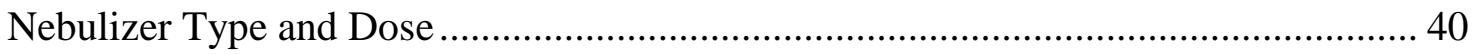

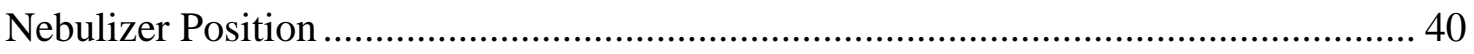

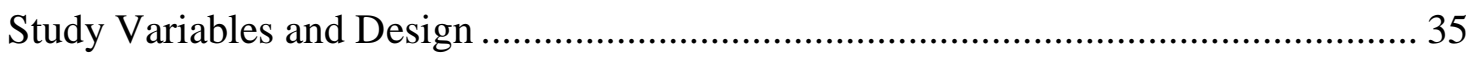

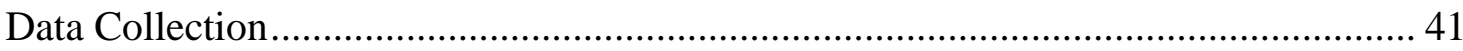

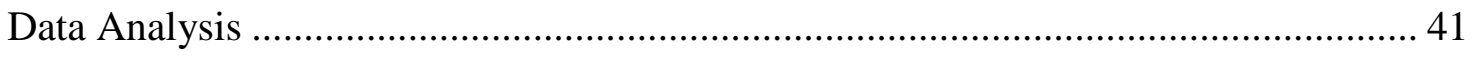

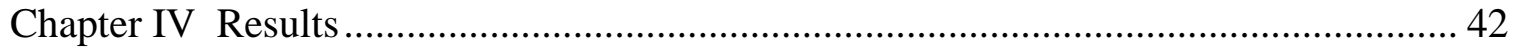

Effect of Nebulizer Position on Aerosol Drug Deposition ........................................... 43

Effect of HFNC and CPAP Systems on Aerosol Drug Delivery .................................. 43

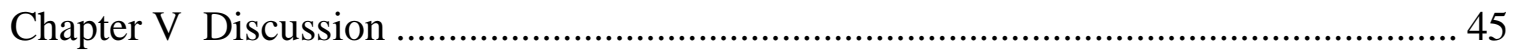

Effect of Nebulizer Position on Aerosol Drug Deposition .......................................... 45

Effect of HFNC and CPAP Systems on Aerosol Delivery .......................................... 47

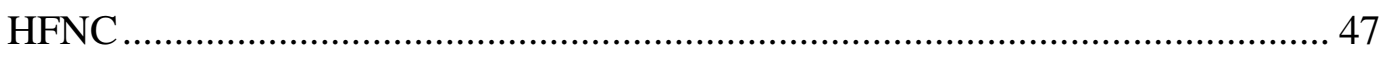

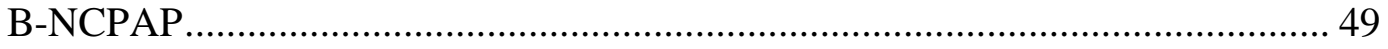

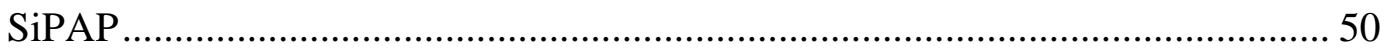

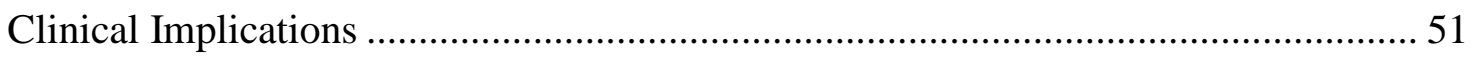

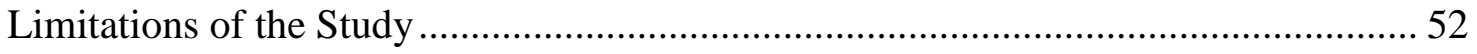

Recommendations for Future Research ............................................................. 52

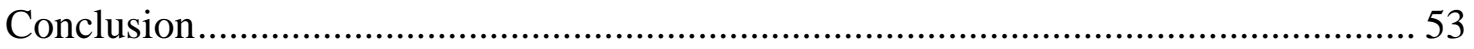




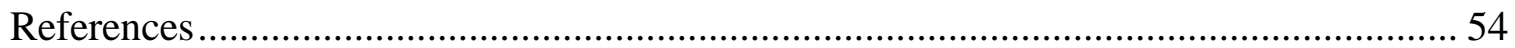




\section{LIST OF TABLES}

Page No.

Table 1. Mean \pm SD of the Inhaled Mass Deposited Distal to the Trachea, Using HFNC,

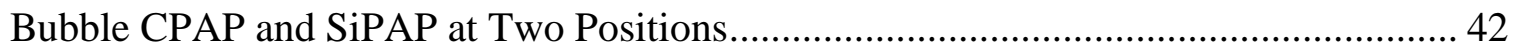

Table 2. Mean Lung Dose Percent \pm SD Delivered Distal to the Trachea with Each

Device, Using Two Nebulizer Positions ............................................................... 42 


\section{LIST OF FIGURES}

Page No.

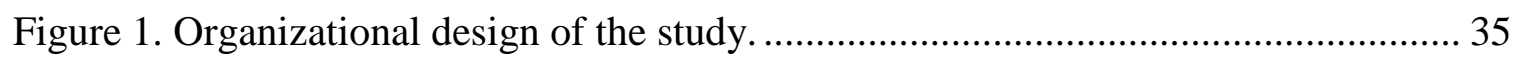

Figure 2. Types of CPAP systems and nasal prongs used in the study. ........................ 36

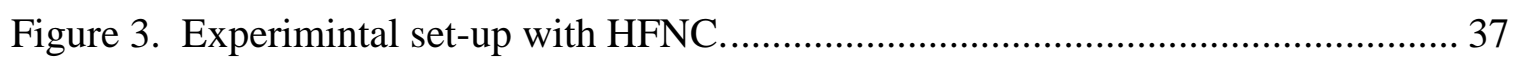

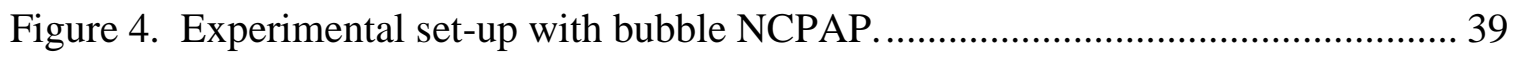

Figure 5. Experimental set-up with SiPAP .................................................... 40

Figure 6 . The mean inhaled mass $(\mu \mathrm{g}) \pm \mathrm{SD}$ of albuterol deposited distal to the trachea

with HFNC, Bubble CPAP, and SiPAP using two nebulizer positions.. ......... 44 


\section{LIST OF ABBREVIATIONS}

\begin{tabular}{ll} 
AARC & American Association of Respiratory Care \\
ANOVA & One-way Analysis of Variance \\
AOP & Apnea of Prematurity \\
APN-C & Aeroneb Professional Nebulizer \\
APN-S & Aeroneb Professional Nebulizer Synchronized \\
B-NCPAP & Bubble Nasal Continuous Positive Airway Pressure \\
BPD & Bronchopulmonary Dysplasia \\
Bpm & Breath per Minute \\
CLD & Chronic Lung Diseases \\
CPAP & Continuous Positive Airway Pressure \\
F\&P & Fisher and Paykel \\
FiO & Fraction of Inspired Oxygen \\
GSD & Geometric Standard Deviation \\
HFNC & High Flow Nasal Cannula \\
HHFNC & Humidified High Flow Nasal Cannula \\
HHHFNC & Heated Humidified High Flow Nasal Cannula \\
I:E & Inspiratory: Expiratory \\
IF-NCPAP & Infant Flow Nasal Continuous Positive Airway Pressure \\
\hline
\end{tabular}




\begin{tabular}{|c|c|}
\hline iNO & Inhaled Nitric Oxide \\
\hline INSURE & Intubation, Surfactant, Extubation \\
\hline IPP & Intrapharyngeal Pressure \\
\hline IRDS & Idiopathic Respiratory Distress Syndrome \\
\hline $\mathrm{JN}$ & Jet Nebulizer \\
\hline LPM & Liters per Minute \\
\hline$\mu \mathrm{g}$ & Microgram \\
\hline$\mu \mathrm{m}$ & Micrometer \\
\hline MMAD & Mass Median Aerodynamic Diameter \\
\hline MMD & Mass Median Diameter \\
\hline $\mathrm{NC}$ & Nasal Cannula \\
\hline NCPAP & Nasal Continuous Positive Airway Pressure \\
\hline NIV & Non-Invasive Ventilation \\
\hline $\mathrm{P}_{\mathrm{a}} \mathrm{CO}_{2}$ & Partial Pressure of Arterial Carbon Dioxide \\
\hline $\mathrm{P}_{\mathrm{a}} \mathrm{O}_{2}$ & Partial Pressure of Arterial Oxygen \\
\hline PDA & Patent Ductus Arteriosis \\
\hline PDP & Positive Distending Pressure \\
\hline PDDS & Pulmonary Drug Delivery System \\
\hline PEEP & Positive End Expiratory Pressure \\
\hline PIP & Peak Inspiratory Pressure \\
\hline pMDI & Pressurized Metered-Dose Inhaler \\
\hline PPROM & Premature Rupture of the Membrane \\
\hline PPV & Positive Pressure Ventilation \\
\hline
\end{tabular}




\begin{tabular}{|c|c|}
\hline RDS & Respiratory Distress Syndrome \\
\hline $\mathrm{RR}$ & Respiratory Rate \\
\hline SAINT & Sophia Anatomical Infant Nose-Throat \\
\hline $\mathrm{S}_{\mathrm{a}} \mathrm{O}_{2}$ & Arterial Oxygen Saturation \\
\hline $\mathrm{SD}$ & Standard Deviation \\
\hline SiPAP & Synchronized Inspiratory Positive Airway Pressure \\
\hline SPECT & Single-Photon Emission Computed Tomography \\
\hline SVN & Small Volume Nebulizer \\
\hline $\mathrm{T}_{\mathrm{c}} \mathrm{CO}_{2}$ & Transcutaneous Carbon Dioxide \\
\hline $\mathrm{T}_{\mathrm{c}} \mathrm{O}_{2}$ & Transcutaneous Oxygen \\
\hline $\mathrm{Ti}$ & Inspiratory Time \\
\hline VF-NCPAP & Variable flow nasal Continuous Positive Airway Pressure \\
\hline VHC & Valved Holding Chamber \\
\hline VMN & Vibrating Mesh Nebulizer \\
\hline V-NCPAP & Ventilator-Derived Nasal Continuous Positive Airway Pressure \\
\hline $\mathrm{V}_{\mathrm{T}}$ & Tidal Volume \\
\hline WOB & Work of Breathing \\
\hline
\end{tabular}




\section{CHAPTER I}

\section{INTRODUCTION}

Aerosol therapy is a common practice for administering medication to infants with pulmonary diseases. Various aerosol devices are used for administering aerosolized medication (Ari \& Fink, 2011).Many of these devices are capable of delivering aerosolized medication directly to the patient or in-line with positive pressure ventilation (PPV) including non-invasive ventilation (NIV) (Ari, Hess, Myers, \& Rau, 2009; Ari \& Restrepo, 2012). However, aerosol device selection can be challenging when patients are infants, particularly because of the following anatomical and physical characteristics: smaller tidal volume, rapid respiratory rate, obligate nose breathing, and small pulmonary reserves. These factors may decrease aerosol deposition (Ari \& Fink, 2011; Ari \& Restrepo, 2012). Previous studies have shown that aerosol delivery via nebulization to infants has been ineffective, with less than 1\% aerosol deposition (Ari \& Fink, 2011; Ari \& Restrepo, 2012). This becomes more challenging with PPV, particularly with NIV since aerosol delivery is further influenced by NIV settings, the position of the nebulizer in relation to the leak port, the aerosol generator type, and the interface used during the treatment (Ari \& Restrepo, 2012).

A common form of non-invasive ventilatory support that is used with infants is continuous positive airway pressure (CPAP). CPAP refers to the application of constant distending positive pressure to the airways of the spontaneously breathing infant during the respiratory cycle. In infants, CPAP is generally used either alone to deliver positive 
pressure or used in conjunction with other inhaled agents (American Association of Respiratory Care [AARC], 2004; DiBlasi, 2009). Moreover, CPAP is a well-established therapeutic option for treatment of preterm infants with respiratory distress syndrome (RDS) (Welzing et al., 2011). CPAP is also used to treat infants with other respiratory disorders, including transient tachypnea of the newborn, meconium aspiration syndrome, pulmonary hypertension, pulmonary hemorrhage, patent ductus arteriosis (PDA), pulmonary edema, tracheomalacia, pulmonary infection, congenital pneumonia, central and obstructive apnea, and apnea of prematurity (AOP) (AARC, 2004; Courtney \& Barrington, 2007).

There are several CPAP delivery systems that are currently applied in practice. The most common CPAP devices used in infants fall under categories of continuous flow, variable flow, and high flow nasal cannula (HFNC), which has recently been used as a CPAP delivery method. Continuous flow devices include ventilator-derived nasal CPAP (V-NCPAP) and bubble nasal CPAP (B-NCPAP). V-NCPAP, also known as a conventional NCPAP, is a constant flow and constant pressure system (DiBlasi, 2009). The expiratory valve creates the pressure level, and it can be adjusted and maintained by varying the expiratory orifice size that is located in the distal expiratory limb (DiBlasi, 2009; Kahn, Habib, \& Courtney, 2008). In contrast, B-NCPAP is a constant flow and variable pressure system (DiBlasi, 2009). The pressure level is created by immersing the expiratory limb of the CPAP tubing into a water chamber, and it can be adjusted by changing its depth. The depth is equal to the desired CPAP level. The constant flow throughout the system generates bubbling in the chamber (Kahn et al., 2008). Variable flow nasal CPAP (VF-NCPAP), also known as an infant flow driver (IF-NCPAP), is a 
variable-flow and constant- pressure device. Changing the flow alters the level of CPAP. This device is also known as "fluidic control NCPAP" because it uses fluidic control to maintain CPAP. During the inspiratory phase, the jet flow moves directly to the infant's airway, and during the expiratory phase it shifts to the expiratory limb. This "fluidic flip" helps to decrease the work of breathing (WOB) during the respiratory cycle (Diblasi, 2009; Nikischin, Petridis, Noeske, Spengler, \& von Bismarck, 2011). HFNC is a new technique that provides continuous distending pressure through the nasal route, or NCPAP, to infants. Multiple studies reported the safety of utilizing HFNC as a method to maintain airways patency, improve gas exchange, and avoid mechanical ventilation. However, the airway pressure produced by HFNC is variable and unpredictable (DiBlasi, 2009; Volsko, Fedor, Amadei, \& Chatburn, 2011; Wilkinson, Andersen, O’Donnell, \& De Paoli, 2011).

Prophylactic treatment of aerosolized agents and therapeutic gases can be delivered via NCPAP. This can avert the need for endotracheal intubation and mechanical ventilation, and also can reduce chronic lung diseases (CLD) and improve the mortality rates in infants (Dhand, 2007; Kahn et al., 2008). Despite that, the current practice in aerosol administration for those infants on NCPAP, who require aerosolized medications, is disconnecting infants from the NCPAP circuit to perform a blow-by aerosolized treatment or to provide manual bag-mask ventilation and bagging for treatment. This technique loses the positive pressure that is required for lung recruitment due to the recurrent disconnecting of the NCPAP circuit. Other clinicians might not administer inhaled agents while the infant is on NCPAP. An alternative to this technique is administering inhaled agents in-line with NCPAP. This can help provide treatment in 
addition to minimizing disconnections of the infant from NCPAP, thereby minimizing interruption of CPAP therapy and loss of pressure. However, clinicians do not use this alternative method because the effectiveness of aerosolized medication through the NCPAP system is still debated, particularly because of the lack of experimental data about how much aerosol is delivered to the infants via a nebulizer when used in-line with the NCPAP system (Farney, Kuehne, \& Gibson, 2010; Smedsaas-Löfvenberg, Nilsson, Moa, \& Axelsson, 1999). In addition, research comparing various CPAP delivery devices is limited, and there is lack of experimental data comparing aerosol delivery via those devices, including VF-NCPAP, B-NCPAP, and HFNC (Kahn et al., 2008). Therefore, more research is required to fill this gap in the literature. For that reason, it is important to conduct this study to fill this gap since it gives a consistent and reliable comparison of aerosol drug delivery via a vibrating mesh nebulizer (VMN) in-line with three frequently used NCPAP devices. This study can identify the types of NCPAP generators that could probably increase aerosol drug delivery using a VMN. Since nebulizer position greatly influences aerosol drug delivery, the study can also identify the proper in-line placement of VMN in the circuit which could possibly optimize aerosol drug delivery during NCPAP therapy. Therefore, this comparison will help to direct clinicians in determining and choosing the most efficient method of aerosol delivery for infants while on NCPAP. It also will help them in decreasing the amount of work when compared with other methods. 


\section{Purpose of the Study}

The purpose of this study was to compare aerosol drug delivery using two different nebulizer positions with VF-NCPAP, B-NCPAP, and HFNC in a simulated spontaneously breathing infant model.

\section{Research Questions}

Q1. How do the types of CPAP systems affect aerosol drug delivery in simulated spontaneously breathing infants?

Q2. Which nebulizer position results in better aerosol deposition in a simulated spontaneously breathing infant model?

\section{Research Hypothesis}

The types of CPAP systems and nebulizer positions used during aerosol therapy will affect aerosol deposition in simulated spontaneously breathing infants. 


\section{CHAPTER II}

\section{REVIEW OF LITERATURE}

This review of literature focuses on CPAP and aerosol research in the infant population. The review of literature was accomplished by searching CINAHL, Web of Science, PubMed, Science Direct, and the Cochrane Library. The terms that were used in this research include the following: continuous positive airway pressure, CPAP, NCPAP, infants, non-invasive ventilation, bubble CPAP, ventilator-derived CPAP, Infant Flow CPAP, synchronized intermittent positive airway pressure (SiPAP), continuous flow CPAP, variable flow CPAP, high flow nasal cannula, HFNC, aerosol delivery, aerosol deposition, aerosolized medication, nebulization, nebulizers, small volume nebulizer (SVN), vibrating mesh nebulizer, VMN, bronchodilators, beta-agonists, blow-by, flowby, ambu bag, resuscitator bag, self-inflating bag, flow-inflating bag, and face mask. These terms were combined in different ways during the search. Only peer-reviewed articles in English published within the last 10 years (2003-2013) were included. However, five studies more than 10 years old were included to fulfill the purpose of this review. This chapter will discuss trends of using NCPAP and HFNC in infants, comparison of different CPAP systems, aerosol delivery in infants, and aerosol delivery via NCPAP systems in infants. 


\section{Trends of Using CPAP and HFNC in Infants}

\section{CPAP}

The first successful clinical use of CPAP was described by Gregory and his colleagues in their landmark report in 1971. They were the first to devise an early CPAP system; it was made of an underwater seal to generate positive end expiratory pressure (PEEP), or simply a bubble CPAP. They conducted their study by applying CPAP through an endotracheal tube $(n=18)$ or a plastic pressure chamber $(n=2)$ in 20 premature infants with idiopathic respiratory distress syndrome (IRDS). The applied CPAP pressure in this study was between 6 to $12 \mathrm{~cm} \mathrm{H}_{2} \mathrm{O}$. Seventeen infants recovered from IRDS. They found that there is no difference in the effects of CPAP applied through either system; with increasing CPAP levels, $\mathrm{P}_{\mathrm{a}} \mathrm{O}_{2}$ increased and minute ventilation decreased without affecting $\mathrm{P}_{\mathrm{a}} \mathrm{CO}_{2}, \mathrm{pH}$, arterial blood pressure, or lung compliance. Therefore, they concluded that CPAP increases $\mathrm{P}_{\mathrm{a}} \mathrm{O}_{2}$ by improving the distribution of ventilation to perfusion instead of increasing alveolar ventilation (Gregory, Kitterman, Phibbs, Tooley, \& Hamilton, 1971).

Then, shortly after their study, Kattwinkel, Fleming, Cha, Fanaroff, andKlaus (1973), researchers at Case Western Reserve University and University Hospitals in Cleveland, Ohio, described the application of CPAP for infants by using nasal prongs. They modified nasopharyngeal cannulas through a chemical curing process into a nasal piece. The small nasal tubes had an outer diameter of $4.5 \mathrm{~mm}$, a length of around $1 \mathrm{~cm}$, and only a small resistance. The rest of the CPAP device was similar to that illustrated by Gregory et al. (1971). NCPAP with a level up to $12 \mathrm{~cm} \mathrm{H}_{2} \mathrm{O}$ was applied to 22 infants with severe RDS whose birth weight was between 960 and 2500 gm, and whose 
gestational age was between 28 and 36 weeks. They found that this method of applying CPAP was successful. Eighteen infants (82\%) had a successful treatment, and they survived without the need for any other form of assisted ventilation. The authors concluded that the application of CPAP by the nasal prongs makes the treatment simple, safe, inexpensive, effective, and readily available to be used with infants.

Both Gregory et al. (1971) and Kattwinkel et al. (1973) demonstrated the use of CPAP as safe, effective, and worth application in infants. Interest in using CPAP increased after that era.

The increased use of CPAP was further demonstrated by a population-based cohort study performed by Roberts, Badgery-Parker, Algert, Bowen, and Nassar (2011) in Australia from 2001 to 2008. Their study was larger and investigated the current population trend in the application of CPAP in infants. The study included around 700,000 infants whose gestational age was $\geq 24$ weeks. The data was collected from live births and hospitalization records. They based their results on the rate of CPAP use over time, infants' characteristics, gestational age, and hospital of CPAP initiation. They found that: from 2001 to 2008 , the use of all ventilatory support in infants increased from 1,480 to 2,486 cases involving 461 to 1,465 infants who received CPAP only. During the same period, the use of mechanical ventilation decreased. Moreover, CPAP use increased from $6 \%$ to $30 \%$ in infants who were more than 32 weeks, predominantly those who began in non-tertiary hospitals (Roberts et al., 2011). Whereas the first two studies illustrated the successful use of CPAP and then NCPAP, this study provided evidence of the current increase of CPAP use, especially with infants whose gestational age is more than 32 weeks. 
Urs, Khan, and Maiya (2009), researchers at a Neonatal Intensive Care Unit, MS Ramaiah Medical College and Teaching Hospital, conducted a prospective observational study involving 50 infants with RDS requiring respiratory support. The aim of this study was to demonstrate the usefulness of B-NCPAP as a primary mode of respiratory support. The researchers used a Fisher and Paykel (F\&P) B-NCPAP. They found that B-NCPAP is a safe and effective therapy for treating mild to moderate RDS. The effectiveness of using B-NCPAP was $80 \%$ (40 out of 50 infants). However, 10 infants had to be placed on PPV. Moreover, the B-NCPAP success rate was $100 \%$ in mild RDS, $93 \%$ in moderate RDS, and only $46.6 \%$ in severe RDS. Therefore, they concluded that B-NCPAP can be used as an effective and simple method of providing primary respiratory support for infants with mild to moderate RDS, and this particularly could be applied in resourcepoor settings.

Koti, Murki, Gaddam, Reddy, and Reddy, (2010), researchers in Hyderabad, India, conducted a prospective analytical study of 56 preterm infants with RDS (gestational age 28-34 weeks) in order to determine the immediate outcomes of BNCPAP on those infants and to determine risk factors related to its failure. They found that only 14 (25\%) infants failed CPAP. Factors that predict CPAP failure were no or limited exposure to antenatal steroids, PDA, white-out on the chest radiography, sepsis, pneumonia, and a Downe's score of $>7$ or $\mathrm{FiO}_{2} \geq 50 \%$ after $15-20$ minutes of CPAP. They also noted that the oxygen requirement and the mortality rate were higher in infants who failed CPAP. Two infants developed pneumothorax, and none had CLD. Therefore, they concluded that infants with one of those predictor factors are at high risk of failing 
CPAP and requiring mechanical ventilation. Nevertheless, B-NCPAP is a safe approach to use on preterm infants with RDS.

CPAP was also examined by Rojas et al. (2009) in their prospective study. This study was conducted to evaluate the effectiveness of NCPAP following extubation, compared to early NCPAP alone in premature infants. Their study was a multicenter, randomized, controlled trial involving 278 premature infants born between 27 and 31 weeks gestation with evidence of respiratory distress. The treatment group involved 142 patients; these patients received the following: intubation, surfactant followed by manual ventilation, extubation, and then NCPAP. The control group involved 138 patients who were assigned to NCPAP alone. The assigned level of CPAP was $6 \mathrm{~cm} \mathrm{H}_{2} \mathrm{O}$ using BNCPAP. They found that NCPAP following surfactant and very brief intubation/ventilation and extubation followed by NCPAP had less need for intubation/ventilation (26\%) compared to the control group (39\%), and less need for surfactant after the first hour of life (12\%) compared with the control group (26\%). Additionally, the treatment group had a lower occurrence of air-leak syndrome (2\%) compared with the control group (9\%), and had less CLD (49\%) compared with the control group (59\%). Therefore, they concluded that intubation, surfactant, and extubation (the INSURE method), without mandatory ventilation, followed by CPAP reduces the need for later mechanical ventilation and the incidence of air-leak syndrome, and appeared to be safe. It also could diminish the CLD caused by mechanical ventilation.

A meta-analysis intervention review was conducted by De Paoli, Davis, Faber, and Morley (2008) to identify the most efficient pressure generator and nasal interface for 
the delivery of NCPAP, reducing the need for additional respiratory support in premature infants. In their review, they only included randomized or quasi-randomized studies that compared a variety of systems of NCPAP pressure sources and/or nasal interfaces in premature infants. Infants who were less than 37 gestational weeks old were extubated to NCPAP after intermittent PPV for RDS or were placed on NCPAP therapy shortly following birth (within 24 hours). They found that the short binasal prongs were a more efficient nasal interface in averting re-intubation and respiratory failure and in decreasing oxygen requirement and respiratory rate (RR) compared to single nasal or nasopharyngeal prongs. Moreover, the Infant Flow system with short binasal prongs was more effective with a reported significantly lower re-intubation rate than Medicorp prongs (short binasal prongs as well). Infants who were placed on an Infant Flow driver had a significant decrease in total hospital stay days. In addition, with the use of Argyle prongs (short binasal prongs), a higher incidence of nasal hyperaemia was reported compared to Hudson prongs. Still, additional research is required that incorporates the longer term outcomes as well as determines the most effective short binasal prongs apparatus, the best CPAP pressure delivery system, and the best CPAP level to use. Studies comparing pressure generators using the Infant Flow system, B-NCPAP system, and ventilator derived CPAP system are needed as well.

\section{HFNC}

The clinical application of HFNC at flow rates of more than 1 LPM has increased with the perception that HFNC might provide benefits similar to those of NCPAP therapy. Spence, Murphy, Kilian, McGongigle, and Kilani (2007), researchers at St. Louis Children's hospital in Missouri, used an observational study of 14 infants who 
were placed on HFNC or NCPAP, and used the intrapharyngeal pressure (IPP) manometry to determine the IPP produced at varying flow rates from 1 up to 5 LPM. They found that an IPP of $1.70 \pm 0.34 \mathrm{~cm} \mathrm{H}_{2} \mathrm{O}$ up to $3.78 \pm 0.44 \mathrm{~cm} \mathrm{H}_{2} \mathrm{O}$ is generated on an average flow of 1 to 5 LPM, respectively. Therefore, they concluded that a significant IPP is delivered by HFNC at flows $\geq 3$ LPM, so HFNC is a possible option to provide CPAP for infants at that flow. A linear relationship was observed between airflow and IPP generated at $\geq 3$ LPM, so the researchers recommended further investigation via a larger study of the variable airway pressure generated by HFNC and its outcome on patient safety.

Kubicka, Limauro, and Darnall (2008) also conducted a study to measure the approximate CPAP level produced by heated humidified high flow nasal cannula (HHHFNC) in infants. Their study included 27 infants whose gestational age was 29.144.7 weeks and whose weight was $835-3735 \mathrm{~g}$ that were treated with HHHFNC (both Vapotherm 2000i and F\&P devices) and excluded infants who had neuromuscular disorders, multiple congenital and/or chromosomal abnormalities, and severe neurologic impairment including a grade 3 or 4 intraventricular hemorrhage. First, they performed bench measurements to estimate the pressure levels that they might encounter in their study using an anesthesia bag as a simulation of an infant's lung and applying three leak sizes around the HFNC. Then, by using a pressure transducer, they obtained measurements of the infants' oral cavity pressure with the mouth closed while infants were on HHHFNC with a flow rates of 1-5 LPM. A small HFNC size was used (outer diameter $0.2 \mathrm{~mm}$ ), and measurements were obtained using the same flow rate and $\mathrm{FiO}_{2}$ as ordered, without altering the flow rate or the $\mathrm{FiO}_{2}$ that the infants were on. To validate 
their measurement method, they obtained mouth pressure measurements for five infants who were on B-NCPAP treatment. Their bench measurements illustrated that there was a linear association between the pressure generated and the flow rate for any given leak size. The highest pressure attained was $4.5 \mathrm{~cm} \mathrm{H}_{2} \mathrm{O}$ with a flow rate of $8 \mathrm{LPM}$ and a leak of $3 \mathrm{~mm}$. Moreover, they stated that the results achieved with both devices (Vapotherm 2000i and F\&P) were parallel to each other, with significantly lower pressures using larger opening sizes. In their infant measurements they found that with the mouth open, no pressure was produced. With the mouth closed, a linear association was found between the oral cavity pressure and both flow rate and weight for infants of $\leq 1500 \mathrm{~g}$. Therefore, they concluded that HHHFNC can generate a clinically significant level of CPAP. However, this CPAP level generated by HFNC is unpredictable except in smaller premature infants with the mouth fully closed. Moreover, the generated pressure depends on the flow rate and infant's weight as well as on the size of the leak around the nasal cannula and the degree of mouth opening. They concluded that HFNC must not be used as a substitute for the delivery of CPAP because of the safety and pressure monitoring issues for utilizing these devices which require additional clinical trials.

In a different study, Wilkinson, Andersen, and Holberton (2008) quantified the pharyngeal pressures generated by HFNC at flow rates of 2 to 8 LPM in premature infants. Their study sample was collected via convenience sample and included 18 stable infants (with a median gestational age of 34 weeks and weight of $1.6 \mathrm{~kg}$ ) who were on HFNC (F\&P) for treatment of RDS, CLD, or AOP. The catheter tip of a pressure transducer was placed into the infants' nasopharynx. Then the HFNC flow was increased to a maximum of 8 LPM and decreased to a minimum of 2 LPM, and the pharyngeal 
pressures were obtained with and without active mouth closure. Active mouth closure was achieved by placing one finger under the infant's chin. They found that there is a strong linear relation between the pharyngeal pressures generated by HFNC and both infant weight and HFNC flow rate, but not mouth closure. With increased weight, the pharyngeal pressure decreased; each $1 \mathrm{~kg}$ increase in weight decreased the average pressure by $1.4 \mathrm{~cm} \mathrm{H}_{2} \mathrm{O}$. By increasing the flow rate, the pharyngeal pressure increased: each $1 \mathrm{LPM}^{-1}$ increase in flow increased the average pressure by $0.8 \mathrm{~cm} \mathrm{H}_{2} \mathrm{O}$. This association could be articulated as pharyngeal pressure $\left(\mathrm{cmH}_{2} \mathrm{O}\right)=0.7+1.1 \mathrm{~F}($ where $\mathrm{F}=$ flow per $\mathrm{kg}$ in $\mathrm{LPM}^{-1} \mathrm{~kg}^{-1}$ ). Therefore, they concluded that using HFNC at a flow rate of 2-8 LPM in premature infants may produce a clinically significant increase in infants' pharyngeal pressure. Nevertheless, the effectiveness and safety of HFNC as a mode of respiratory support requires verification in large clinical trials prior to its widespread implementation in clinical settings.

All three studies_-Spence et al.(2007), Kubicka et al.(2008), and Wilkinson et al.(2008)_ drew similar conclusions and proved that HFNC at a flow rate of more than 1 LPM can produce clinically significant CPAP levels in preterm infants. Both Kubicka et al. (2008) and Wilkinson et al. (2008) verify that there is a linear relationship between the infant's weight and the flow rate with the pressure generated. However, they have contradictory results regarding mouth closure. Although HFNC proved to be a possible option to provide CPAP, a safety concern of unpredictable levels of CPAP might be encountered without the ability to continuously measure the CPAP level while infants are on HFNC, which could restrict clinicians from using HFNC as a CPAP delivery system. 


\section{Comparison of CPAP Systems}

\section{V-NCPAP Versus B-NCPAP}

Many NCPAP devices are currently available. However, only a few studies comparing different NCPAP devices are available. A study by Tagare, Kadam, Vaidya, Pandit, and Patole (2009) was a pilot randomized control trial involving 30 premature neonates with a gestational age of less than 37 weeks and with an oxygen requirement of more than $30 \%$. Tagare et al. studied the safety and efficiency of B-NCPAP versus VNCPAP in premature infants with moderate respiratory distress. The study results were comparable in both devices, B-NCPAP and V-NCPAP, including: the mean duration of CPAP was 25.5 hours on V-NCPAP versus 25 hours on B-NCPAP; the success rate was $80 \%$ in V-NCPAP versus $87 \%$ in B-NCPAP; and displacement was a common problem, with $67 \%$ in both groups. However, a pneumothorax developed in two neonates in the VNCPAP group. Therefore, they concluded that B-NCPAP could be a promising approach for preterm neonates with mild respiratory distress. They also noted that it is an effective and safe approach for respiratory distress. This study was limited by its small sample size and by not including the CPAP level that was used for both devices or measuring the respiratory parameters that could be affected by CPAP application.

Bahman-Bijari, Malekiyan, Niknafs, and Baneshi (2011) conducted a similar study comparing V-NCPAP and B-NCPAP. This was a randomized prospective clinical study, which involved 50 preterm infants whose weight was between $1 \mathrm{~kg}$ and $2 \mathrm{~kg}$ and who had respiratory distress. The authors compared the effectiveness and the complications between B-NCPAP and V-NCPAP devices. The researchers also compared the survival rate, the duration of oxygen therapy, the duration of hospital stay, and 
hospital costs. They found that both B-NCPAP and V-NCPAP had equivalent demographic characteristics. B-NCPAP was effective in $96 \%$ of patients versus $72 \%$ in V-NCPAP. B-NCPAP had lower failure rate than the V-NCPAP. The estimated survival rate at 24 hours was higher for B-NCPAP $(100 \%)$ than for V-NCPAP $(77 \%)$, and the 48hour survival rate was also higher for B-NCPAP (100\%) than for V-NCPAP (71\%). Moreover, higher hospital costs were found for V-NCPAP compared to B-NCPAP. Therefore, the authors concluded that B-NCPAP was an efficient treatment for infants suffering from respiratory distress and that it decreased the duration of the hospital stay. Compared to V-NCPAP, B-NCPAP is mainly used because of its lower cost.

Another study conducted by Courtney, Kahn, Singh, and Habib (2011) was a randomized crossover study. This study involved only 18 premature infants whose weight was less than $1500 \mathrm{~g}$ and who were receiving NCPAP for mild respiratory distress. It compared WOB and other short-term respiratory outcomes including gas exchange between B-NCPAP and V-NCPAP at comparable delivered nasal prong pressures. This study found that there was no difference between B-NCPAP and V-NCPAP on WOB or on most respiratory parameters, which included tidal volume $\left(\mathrm{V}_{\mathrm{T}}\right), \mathrm{RR}$, phase angle, minute ventilation, lung compliance, heart rate, and $\mathrm{S}_{\mathrm{a}} \mathrm{O}_{2}$. In addition, there was no significant difference in $\mathrm{T}_{c} \mathrm{CO}_{2}$ between those two devices; however, a higher $\mathrm{T}_{\mathrm{c}} \mathrm{O}_{2}$ was noted with B-NCPAP compared to V-NCPAP (Courtney et al., 2011). Therefore, the researchers concluded that when equivalent delivered pressures are guaranteed in the nasal prong, B-NCPAP and V-NCPAP have similar effects on WOB and other respiratory parameters. Nevertheless, further research is required to investigate the improved oxygenation that was observed with B-NCPAP and to quantify the oscillation's 
high-frequency content distal to the nasal prongs in B-NCPAP. The study was limited by including only relatively healthy, moderately premature infants, and studying the outcomes after only 5 minutes on each device. Nevertheless, this study was the first to compare B-NCPAP and V-NCPAP in preterm infants at equivalent delivered nasal prong pressures.

Kahn, Courtney, Steele, and Habib (2007) performed a study to compare the actual delivered pressure versus the intended pressure through intra-prong, proximalairway, and distal-airway via V-NCPAP and B-NCPAP devices. The settings that they used in their study were flow rates of 4, 6, 8, 10, and 12 LPM and NCPAP levels of 4, 6, and $8 \mathrm{~cm} \mathrm{H}_{2} \mathrm{O}$. These measurements were performed during small, large, and without leak conditions. The researchers found that unlike V-NCPAP, B-NCPAP delivered a higher pressure than the desired set levels. When these settings were tested under leak conditions, they found that an excess pressure was also present through prong and intraairway B-NCPAP. Therefore, they concluded that the ability of the ventilator to selfadjust permits an equivalent actual versus set V-NCPAP pressure level. On the other hand, even with the presence of a significant nasal prong leak, the intra-prong and intraairway pressure generated by the B-NCPAP was higher at increasing flows than the set pressure. Moreover, the oscillations illustrating B-NCPAP were noticeably diminished between the proximal and distal airways. Thus, it is questionable that B-NCPAP creates lung recruitment or ventilation by this method. Finally, the set pressure of B-NCPAP that is determined by the depth of B-NCPAP tube is highly inaccurate; therefore, clinicians have to rely on intra-prong pressure measurements in order to deliver the desired pressure. 
Kahn et al.'s (2008) study involved 12 preterm infants and conducted in order to compare the actual (delivered) intra-prong continuous positive airway pressure with the intended (set) NCPAP in V-NCPAP and B-NCPAP delivery and illustrated the flow dependence of B-NCPAP delivery in preterm infants. The researchers measured the intraprong pressures while increasing the flow, and then while keeping the flow constant. They found and concluded that in V-NCPAP the actual pressure was almost equal to the set pressure, whereas in B-NCPAP the actual (delivered) intra-prong pressure increased as the flow rate increased and was highly flow dependent.

\section{V-NCPAP Versus IF-NCPAP}

Bober et al. (2012) conducted a multicenter randomized controlled trial to compare treatment outcomes when using variable flow IF-NCPAP with constant flow VNCPAP among very low birth weight infants who were receiving NCPAP electively to prevent intubation or as a weaning from mechanical ventilation. A total of 276 infants whose weight was between $750-1500 \mathrm{~g}$ and a gestational age of $\leq 32$ weeks were randomly assigned to receive the IF-NCPAP system (VIASYS) or the constant flow VNCPAP (baby log 8000 plus). About half (51\%) of the infants were placed on an IFNCPAP, while $49 \%$ of the infants were placed on a constant flow V-NCPAP. A $75 \%$ success rate of treatment, described as no need for intubation or re-intubation, was found with a non-statistically significant benefit from using an IF device. Moreover, a statistically significant reduction in the occurrence of nasal complications and necrotizing enterocolitis were seen among the IF group. 


\section{B-NCPAP Versus IF-NCPAP}

Malloy, Glynn, Pullar, Delaney, and Greenspan (2003) conducted a study to compare an IF-NCPAP device and a B-NCPAP device in 14 infants with RDS (GA $\leq 32$ weeks). Infants were placed on $5 \mathrm{~cm} \mathrm{H}_{2} \mathrm{O}$ of CPAP on either IF-NCPAP or B-NCPAP. Weight loss during the first week of life, WOB, and abdominal distension were observed. This study found that the average number of days spent on CPAP was 8.7 for those infants placed on B-NCPAP and 7.7 days for those infants placed on IF-NCPAP. During a 7-day period, an average weight loss of $122.5 \mathrm{~g}$ was seen in the B-NCPAP group and $51.75 \mathrm{~g}$ in the IF group. Two infants failed the B-NCPAP, while no infants failed the IF treatment. Therefore, they concluded that the increase in expiratory resistance from the continuous flow in the B-NCPAP device may cause an increase in WOB and abdominal distension, which explains the loss of weight trend that was seen in the first week of the infants' lives.

Liptsen et al. (2005) conducted a study in two centers-Cooper Hospital/University Medical Center and Schneider Children's Hospital—in order to compare work of breathing and breathing asynchrony between B-NCPAP and VFNCPAP in premature infants. The study involved 18 preterm neonates with a birth weight of less than $1500 \mathrm{~g}$ who required NCPAP for mild respiratory distress. All infants were placed on B-NCPAP and VF-NCPAP at pressures of 8, 6, 4, and $0 \mathrm{cmH}_{2} \mathrm{O}$. A calibrated respiratory inductance plethysmography was used to measure the tidal volumes, and intrapleural pressure was used to measure the esophageal pressure. Then they calculated the inspiratory and resistive WOB using pressure-volume data and assessed the breathing asynchrony by phase angle. They found that NCPAP decreased inspiratory $\mathrm{WOB}, \mathrm{V}_{\mathrm{T}}$, 
and minute ventilation. B-NCPAP, relative to $0 \mathrm{cmH}_{2} \mathrm{O}$, did not reduce the resistive WOB. Moreover, resistive WOB, RR, and phase angle were all reduced with VF-NCPAP compared to B-NCPAP. Therefore, they concluded that the more labored and asynchronous breathing observed with B-NCPAP can cause higher failure rates compared to VF-NCPAP.

\section{HFNC Versus NCPAP}

Sreenan, Lemke, Osiovich, and Hudson-Mason (2001), researchers at Royal Alexandra Hospital in Canada, conducted a crossover study of 40 premature infants who had clinically significant AOP. The researchers sought to determine the required nasal cannula (NC) flow to produce positive distending pressure (PDP) equal to that provided by NCPAP at $6 \mathrm{~cm} \mathrm{H}_{2} \mathrm{O}$ and to compare the effectiveness of HFNC with NCPAP in the management of AOP. They found no difference between the PDP generated by NCPAP at $6 \mathrm{~cm} \mathrm{H} 2 \mathrm{O}$ and by NC. They also found that the NC flow needed to create a PDP compared to that produced with NCPAP increases with increasing infants' weight. They also concluded that the difference in the frequency and duration of apnea, bradycardia, or desaturation between NC and NCPAP was insignificant. Finally, they noted no side effects of NC use such as those related to NCPAP. Therefore, they concluded that NC at a flow of 1-2.5 LPM can generate PDP in infants less than $2.0 \mathrm{~kg}$ and that it is easy to perform, well-tolerable, and as effective as NCPAP in the management of AOP. For those reasons, they recommended using HFNC as a method of delivering PDP in infants with AOP.

Campbell, Shah, Shah, and Kelly (2006) conducted a study on 40 premature infants (birth weight of $\leq 1250 \mathrm{~g}$ ) to compare the usefulness of CPAP created by HFNC 
with conventional NCPAP in preventing re-intubation. Infants were randomly assigned to HFNC (n=20) or to IF-NCPAP (VIASYS) (n=20) immediately after extubation. They found that out of 20 infants who were placed on HFNC, 12 infants were re-intubated. Only three infants who were placed on IF failed extubation. Increase in $\mathrm{O}_{2}$ requirement, apnea frequency, and bradycardia after extubation were noted in the HFNC group. Therefore, they concluded that administering CPAP by HFNC is not as effective an alternative as IF-NCPAP in maintaining extubation status in premature infants.

Shoemaker, Pierce, Yoder, and DiGeronimo (2007), researchers at two Texas regional medical centers, Wilford Hall USAF Medical Center and Christus Santa Rosa Children's Hospital, used a retrospective study to evaluate the usage frequency, safety, and clinical efficacy of the humidified high flow nasal cannula (HHFNC) and to compare its outcome to that of NCPAP. They found that through the two study periods, the usage of HHFNC increased $64 \%$ following its introduction in all gestational age infants while the NCPAP usage decreased from $19 \%$ to $4 \%$. Moreover, at some point in the hospital stay of infants who are less than 30 weeks gestational age, only $12 \%$ of them received NCPAP while 95\% received HHFNC. In comparing both HHFNC and NCPAP, they found that there were no differences in adverse outcomes; however, after introduction of HHFNC, the number of days on ventilator per patient was decreased from 19.4 to 9.9 days. Furthermore, intubation because of failing early NCPAP was more noticeable compared to early HHFNC. Therefore, they concluded that premature infants tolerate HHFNC well and that there were no significant differences in adverse outcomes when comparing infants managed by HHFNC or by NCPAP. Nevertheless, further research is required to identify the safety and the efficacy of HHFNC in comparison to NCPAP. 
Wilkinson et al. (2011) conducted an intervention review that included randomized and quasi-randomized studies to compare the effectiveness and safety of HFNC instantly following birth or following extubation with other types of non-invasive respiratory support in premature infants. This review identified four studies comparing NCPAP, HHFNC, non-HHFNC, the provided flow rates, and the indication for respiratory support. The findings of this review include the following: using HFNC as a primary respiratory support following birth resulted in a similar rate of treatment failure as when using NCPAP; there was a higher re-intubation rate in infants treated with HFNC compared to infants treated with NCPAP; HHFNC and non-HHFNC had comparable re-intubation rates; and there was no difference in extubation success between the two different forms of apparatus (F\&P and Vapotherm) utilized to deliver HHFNC.

\section{Aerosol Delivery in Infants}

Schüepp et al. (2005) conducted an in-vitro study to determine the optimal aerosol particle size for inhalation therapy in infants. They also examined the effect of breathing patterns and aerosol particle size on aerosol lung deposition using an infant upper airway lung model (Sophia Anatomical Infant Nose-Throat [SAINT] model). To measure aerosol delivery, a VMN (eFlow) with a facemask was used to aerosolize Budesol (Budesonide solution) into the upper airway of a 9-month-old lung model. Breathing parameters with a fixed $\mathrm{RR}$ of $30 \mathrm{bpm}$ and a $\mathrm{V}_{\mathrm{T}}$ of $50 \mathrm{ml}, 100 \mathrm{ml}$, and $200 \mathrm{ml}$ were used. Then, breathing parameters were set at a fixed $V_{T}$ of 100 and $R R$ of $30 \mathrm{bpm}, 60 \mathrm{bpm}$, and $78 \mathrm{bpm}$, respectively. They found that with increasing $\mathrm{V}_{\mathrm{T}}$ and with increasing $\mathrm{RR}$, the nominal dose percentage of lung deposition (5.8-30.3\%) diminished. Also, a negative 
relationship was illustrated between the mass median aerodynamic diameter (MMAD) (2.4-3.4 $\mu \mathrm{m}$ ) with increasing $\mathrm{V}_{\mathrm{T}}$ and with increasing RR. For all simulated breathing patterns, particle size distributions that were available as lung deposition have a MMAD of $2.4 \mu \mathrm{m}$ and a Geometric Standard Deviation (GSD) of 1.56. Therefore, the researchers concluded that a MMAD of less than $2.4 \mu \mathrm{m}$ is the optimal aerosol particle size for aerosol therapy for infants.

Another study involving 12 infants (mean age 0.8 years) and 8 children (mean age 10.8 years) with cystic fibrosis was conducted by Chua et al. (1994) to measure the effect of age on aerosol lung deposition. A radiolabelled normal saline was given using a Turrent nebulizer with a facemask for infants and with a facemask and mouthpiece for children. After aerosol inhalation, Planar and single-Photon emission computed tomography (SPECT) scans were taken. They found that in infants, the median lung deposition was $1.3 \%$ and that in children, the median lung deposition was $2.7 \%$. There was no difference between the facemask and the mouthpiece median lung deposition in children. The total aerosol lung deposition was lower in infants than in older children. Amirav, Balanov, Gorenberg, Groshar, and Luder (2003) performed a study involving 14 wheezy infants with a mean age of 8 months to compare the effectiveness of aerosol lung deposition via a facemask or a prototype hood using a SVN. A dose of 99mTc Salbutamol (a radiolabelled solution) was randomly administered by either the facemask or the hood with the SVN using a flow rate of 8 LPM. Gamma scintigraphy was used to evaluate the distribution of Salbutamol. No significant difference in total lung deposition between the mask and hood was found in this study. The mean total lung deposition with the facemask was $2.4 \%$ and with the hood was $2.6 \%$. 
Restrepo, Dickson, Rau, and Gardenhire (2006) conducted an in-vitro study to investigate the effect of increasing distance on the total inhaled drug mass using a standard pediatric mask compared with a T-piece. A simulated spontaneously breathing toddler lung model with breathing parameters of $\mathrm{V}_{\mathrm{T}} 60 \mathrm{ml}$, RR $30 \mathrm{bpm}$, I:E 1:2, and a flow rate of 3.6 LPM were used in this study. A set of five nebulizers (MistyNeb) filled with $3 \mathrm{ml}$ of $3.0 \mathrm{mg}$ of albuterol sulfate were used with a standard pediatric mask and with a T-piece that was capped at one end. They were positioned at the inlet of a pediatric test lung with a distance of $0 \mathrm{~cm}, 1 \mathrm{~cm}$, and $2 \mathrm{~cm}$. They found that with the facemask, the inhaled drug mass percentages were $2.88 \pm 0.79 \%, 1.61 \pm 0.65 \%$, and $1.3 \pm 0.42 \%$ at 0 $\mathrm{cm}, 1 \mathrm{~cm}$, and $2 \mathrm{~cm}$, respectively. With the T-piece, the inhaled drug mass percentages were $4.14 \pm 1.37 \%, 3.77 \pm 1.04 \%$, and $3.45 \pm 0.62 \%$ at $0 \mathrm{~cm}, 1 \mathrm{~cm}$, and $2 \mathrm{~cm}$, respectively. A statistically higher inhaled drug mass was found with the T-piece compared to the mask. With increased distance, the inhaled drug mass significantly decreased with both the mask and the T-piece.

Al Sultan et al. (2012) conducted an in-vitro study to measure aerosol drug delivery in a simulated pediatric lung model using a jet nebulizer (JN), a VMN, and a pressurized metered-dose inhaler/valved holding chamber (pMDI/VHC) in conjunction with a manual resuscitator bag. Using a flow rate of 10 LPM, a pediatric resuscitator bag (Ambu SPUR II Disposable Resuscitator) was connected to each aerosol generator, attached to an infant facemask, and placed firmly on the SAINT model. With each aerosol generator, active and passive breathing patterns were applied. Breathing parameters of $\mathrm{V}_{\mathrm{T}} 100 \mathrm{ml}$, RR $30 \mathrm{bpm}, \mathrm{I}: \mathrm{E} 1: 4$ were used in this study. The authors found that the delivered mean inhaled percentage of albuterol by pMDI/VHC $(19.55 \%$ and 
$27.84 \%)$ was greater than by $\mathrm{JN}(2.57 \%$ and $2.45 \%)$ or $\mathrm{VMN}(5.99 \%$ and $7.62 \%)$ in both passive and active breathing patterns. The VMN was more effective (with $>2$ fold greater) in aerosol delivery compared to JN. In both breathing patterns, the pMDI/VHC had a higher amount of lung deposition than VMN. Moreover, the same amount of aerosol deposition was noted using the JN during passive and active breathing. During active breathing, the VMN was more effective than the $\mathrm{JN}(p=0.157$ and $p=0.729$, respectively). The greatest deposition was noted with the pMDI/VHC in the simulated spontaneously breathing lung model $(p=0.013)$.

Dubus et al. (2005), researchers in France, conducted a study to evaluate the aerosol delivery in a neonatal ventilation model using a conventional nebulizer (MistyNeb), an electronic micropump nebulizer working continuously (Aeroneb Professional nebulizer [APN-C]), and another APN operating synchronously with inspiration (Aeroneb Professional nebulizer synchronized [APN-S]). For their aerosol, they used 99mTc-DTPA. The neonatal settings were peak inspiratory pressure (PIP) 12 14 mbar, PEEP 2, I:E 1:2, and RR $40 \mathrm{bpm}$. The researchers found that both APN-S and APN-C delivered more aerosol to the lungs than MistyNeb (14\%, 12.6\%, and $0.5 \%)$. APN-C had shorter aerosol delivery duration (2 min compared to 6 min for APN-S and 10 min for MistyNeb). Therefore, the researchers of this study concluded that, using an animal model of ventilated neonates, the aerosol administration is more efficient using electronic micropump nebulizers.

\section{Aerosol Delivery via NCPAP Systems}

Similar to comparing and finding the proper NCPAP device to use with infants, optimal aerosol administration with NCPAP is essential in treating those infants who 
require nebulized drugs while on NCPAP. A few studies have been conducted on this matter. Some of these that focus on inhaled agents via NCPAP are incorporated into this review. All studies that look at aerosolized bronchodilators in-line with NCPAP are included as well.

In 1999, Smedsaas-Löfvenberg et al., researchers at the Department of Paediatrics, County Hospital, Mid Sweden University in Ostersund, Sweden, modified a NCPAP system to allow nebulized drugs to flow through a tube to the nasal prongs and into the infants' airways. The only difference between this modified NCPAP system and the conventional IF-NCPAP system is the integrated aerosol canal. They started their study by nebulizing ribavirin and surfactant to measure the aerosols' particle size. It was performed at driving pressures of 2-3 bar, equivalent to a gas flow of 8-10 LPM. They found that the mass median diameter (MMD) of aerosolized surfactant and ribavirin was $0.7-0.9 \mu \mathrm{m}$, and less than $16 \%$ of the aerosol had a particle diameter above $1.9 \mu \mathrm{m}$. Then, they treated the infants with nebulized ribavirin and surfactant. Five infants (gestational age of 2 weeks to 35 weeks) with bronchiolitis were included. The infants were treated with CPAP for 2-9 days, and used ribavirin for 18 hours per a 24-hour period for 1-3 days. Only one infant had to be intubated because she demonstrated signs of exhaustion and increased $\mathrm{P}_{\mathrm{a}} \mathrm{CO}_{2}$. They concluded that nebulized drugs via the NCPAP system is a feasible method for medication delivery, but recommended that a multi-center prospective randomized trial for aerosolized drugs with NCPAP be conducted. A strength of this study is that it was the first to modify a NCPAP system to allow the administration of aerosolized drugs through the nasal prongs. They also performed an in- 
vitro study to measure the aerosols' particle size, followed by a clinical trial. However, the sample size of this study is very small, including only five infants.

The next study was conducted by Welzing et al. (2011), researchers at the Department of Neonatology, Children's Hospital at the University of Bonn in Bonn, Germany, also examined the administration of an inhaled agent with NCPAP. This study is the first to report on combining NCPAP with inhaled nitric oxide (iNO) for treatment of lung hypoplasia and persistent fetal circulation in infants with very early premature rupture of the membrane (PPROM) and prolonged severe oligohydraminas. The researchers noted that before initiating NCPAP with iNO, they applied the INSURE method (intubation, surfactant, extubation) for those infants included in their study $(n=7)$. Then researchers placed the premature infants on mechanical ventilation and iNO, which was started within the first hour of the infants' lives. After that, all infants were switched to iNO in-line with IF-NCPAP. The authors' major findings were that all patients in their study survived to discharge; six out of seven were stabilized on NCPAP with iNO only; only two infants showed evidence of CLD, and only one developed pneumothorax while on mechanical ventilation. Therefore, the authors of this study believed that combining NCPAP with iNO is a promising new therapeutic approach that can be efficiently and safely used in premature infants with lung hypoplasia and persistent fetal circulation. Nevertheless, the authors emphasized the need for a randomized, controlled trial that compares iNO combined with NCPAP to iNO with mechanical ventilation. Also, they stated that further research is needed focusing on whether combining iNO with NCPAP is effective primarily in moderate lung hypoplasia cases or in infants having severe lung hypoplasia. Welzing et al. showed the feasibility of combining NCPAP with iNO. 
However, the study was limited by the small sample size, the retrospective nature of the study, and a missing control group.

Finer et al. (2010), at the University of California San Diego, also conducted an open label, pilot study to verify the safety and usefulness of combining a prophylactic aerosolized Aerosurf, a synthetic surfactant, with NCPAP for use with premature neonates at risk of RDS. They used a VMN (Aeroneb Pro) to aerosolize 20mg/ml Aerosurf. Seventeen infants were enrolled in the study. The researchers found that Aerosurf was well-tolerated by the infants. A transient desaturation, which did not include bradycardia or hypotension, was observed for the duration of dosing. They also noted that the output rate of the Aeroneb was variable. This led to dissimilar average distributed drug volume per treatment per patient. All infants survived with $29.4 \%$ requiring consequent endotracheal surfactant replacement therapy. At 24 hours, $23.5 \%$ of infants were diagnosed with RDS, and at 28 days of life, $11.8 \%$ were diagnosed with bronchopulmonary dysplasia (BPD). The mean $\mathrm{FiO}_{2}$ was 0.4 at baseline and 0.32 at 4 hours after treatment. Therefore, they concluded that administering Aerosurf via NCPAP can be safely used in premature infants at risk of RDS. This method could offer an alternative administration of surfactant as opposed to via an endotracheal tube. Nevertheless, additional research is needed to assess this delivery method. This study noted that the measured output rate of the Aeroneb was variable; however, they did not specify whether this variability was caused by the NCPAP system, the nebulizer itself, or the surfactant.

Smedsaas-Löfvenberg et al. (1999) conducted both an in-vitro and then a clinical trial. Welzing et al. (2011) and Finer et al.'s (2010) studies were clinical trials. Both 
Smedsaas-Löfvenberg et al. (1999) and Welzing et al. (2011) used IF-NCPAP in their studies. Those three clinical trials are limited by their very small sample size. Unlike those studies, the following two studies by Fink \& Kakade (2004) and Farney, Kuehne, and Gibson (2010) are in-vitro studies also measuring aerosol delivery via the NCPAP system.

An in-vitro infant model ventilation during NCPAP was designed by Fink \& Kakade (2004) to examine the capability of two aerosol delivery devices: the Aeroneb Pro and a low volume Prototype Pulmonary Drug Delivery System (PDDS) that is useful for positioning proximal to the infants airway. A VMN (Aerogen OnQ micropump aerosol generator) was combined with both devices. Differentiation between aerosol delivery and condensation to the infants' model was also examined in this study. The researcher used a reciprocating pump animal ventilator with infant parameters $\left(\mathrm{V}_{\mathrm{T}} 10 \mathrm{ml}\right.$, and respiratory rate $40 \mathrm{bpm}$ ), and a constant airflow of $10 \mathrm{LPM}$ to create a CPAP level of $5 \mathrm{~cm} \mathrm{H}_{2} \mathrm{O}$. The aerosolized drug used with the nebulizer systems in this study was albuterol sulfate $0.5 \mathrm{ml}(0.5 \%)$. The researcher placed the Aeroneb Pro on the inspiratory limb of the CPAP circuit and the PDDS nebulizer between the main flow of the CPAP and the nasal prongs. Then, to distinguish between aerosol delivery versus condensation, a filter was placed superior to the nasal prongs and the researcher performed a further run with the PDDS nebulizer. Fink \& Kakade found that the lung deposition with Aeroneb Pro was $1.3 \pm 0.8 \%$. The PDDS nebulizer delivered $22.5 \pm 1.7 \%$ when the filter was placed at level of the nasal prongs adaptor, and $12.8 \pm 2.7 \%$ when the filter was placed above the nasal prongs. According to the findings of this study, the PDDS nebulizer delivered more drug throughout the nasal prongs of CPAP compared to the Aeroneb Pro 
nebulizer when placed in usual orientation. Moreover, when the filter was placed superior to the nasal prongs, up to $40 \%$ of the Albuterol was condensate and not aerosolized. The high effectiveness of combining aerosol delivery with a NCPAP in this infant model implies potential opportunities for administering active medications to the infants' airways. This study provided a strong comparison between two types of nebulizers to administer inhaled medication with NCPAP.

Another similar in-vitro study was conducted by Farney, Kuehne, and Gibson (2010) at Nationwide Children's Hospital in Columbus, Ohio, using a test lung to evaluate the particle deposition of aerosol in the systemic circuit using an Aerogen micropump nebulizer through a VF-NCPAP system. They used $3 \mathrm{ml}$ of TC99mTcDTDA. Then a VMN (Aerogen micropump aerosol generator) was positioned along the lines of a Cardinal IF-NCPAP generator system. They placed the nebulizer both proximally and distally in the circuit. A simulated patient effort at a minute volume of 0.4 L was used. They performed 15 sessions, and each session was run over 15 minutes. They found that when the nebulizer was positioned at the heater $(n=6)$, the average medication delivery was $0.32 \pm 0.36 \%$. When the Aerogen was placed 18 inches from the prongs $(n=9)$, the average medication delivery was $21.41 \pm 11.49 \%$. They found that when the nebulizer was located closer to the patient, the delivery of aerosolized medication was greater. Therefore, they anticipated a change in practice concerning the placement of in-line nebulizers (Farney et al., 2010).

Both studies_Fink \& Kakade (2004) and Farney et al. (2010) — used an Aerogen nebulizer and compared different nebulizer positions in the CPAP circuit. In Fink \& Kakade's study (2004), a constant flow NCPAP system was used as opposed to the VF- 
NCPAP system used in Farney et al.'s study (2010). Fink \& Kakade found that aerosol delivery is better (22.5\%) when placing the PDDS at the level of the nasal prongs adaptor, while Farney et al. found that the aerosol delivery is better $(21.41 \%)$ when placing the Aerogen closer to the patient. Nevertheless, both deliver a comparable percentage of aerosol.

Only one study was found that compares aerosol drug delivery with different CPAP systems. Zweifel (2010) conducted an in-vitro study to measure the effectiveness of aerosol drug delivery using different nebulizers with two different CPAP systems using a SAINT lung model of a 9-month-old infant. Three type of nebulizers, eFlow baby, Aeroneb Pro, and Cirrus, were used to nebulize $2 \mathrm{ml}$ of Salbutamol (Ventolin; $5 \mathrm{mg} / \mathrm{ml}$ ) in-line with Evita 4 (Drager Medical) and B-CPAP (F\&P Healthcare) using different breathing parameters $\left(\mathrm{V}_{\mathrm{T}} 50 \mathrm{ml}, 100 \mathrm{ml}\right.$, and $150 \mathrm{ml}$, RR $30 \mathrm{bpm}$, Ti 0.42 second). A PEEP of $3 \mathrm{~cm} \mathrm{H}_{2} \mathrm{O}$ was used in both CPAP devices. A face mask (Vygon) was attached to the nebulizers and placed between the SAINT model and the CPAP system. Aerosol was measured through the infant lung model. The influence of humidification on aerosol delivery was also examined. The researcher found that there is no difference in lung deposition between the two CPAP systems with the nebulizers used. With both CPAP systems, a significantly higher mean lung deposition $(3.7 \%$ and $2.5 \%$, $2.1 \%$ and $2 \%, 1.2 \%$ and $1.6 \%$, respectively, with each nebulizer) and a higher mean model deposition ( $46.2 \%$ and $49.7 \%$ ) via the eFlow baby nebulizer was found compared to the Cirrus nebulizer and the Aeroneb Pro nebulizer. When the effect of humidification was investigated, a significantly higher mean \pm standard deviation (SD) lung dose from the eFlow baby nebulizer through the Evita 4 was found $(11.6 \pm 3.5 \%)$ without 
humidification compared with $(3.7 \pm 1.3 \%)$ using humidification. Higher face deposition was also reported with all systems. The author concluded that although the lung deposition was low when using efficient nebulizers, a significantly higher dose was delivered to the SAINT lung model.

Two studies dealing with aerosol drug delivery via HFNC were found. The first study was conducted by Bhashyam et al. (2008), researchers at the University of Pittsburgh in Pennsylvania. This was an in-vitro study of aerosol size and output designed to evaluate the possibility of delivering aerosols through nasal cannula. They utilized a VMN (Aerogen Solo) that was placed downstream of a heater/humidifier system, followed by a nasal cannula and an aerosol collection device. The study tested adult, pediatric, and infant cannulas with and without the use of a breathing simulator on an oxygen flow of 3 LPM. The researchers found that the total output of the cannula ranged from $8.4-25.1 \%$ and $18.6-26.9 \%$ of the loaded dose. Moreover, output doses were considerably higher in the pediatric and adult cannulas comparing with the infant cannula. The aerosol's median diameters from the adult cannula were $2.2 \pm 0.2 \mu \mathrm{m}$ and $1.9 \pm 0.3 \mu \mathrm{m}$ from the pediatric cannula. The size of $90 \%$ of the aerosol volume was smaller than $4.2 \pm 0.4 \mu \mathrm{m}$ in the adult cannula and $3.8 \pm 0.5 \mu \mathrm{m}$ in the pediatric cannula. The researchers concluded that a HHFNC system can efficiently deliver aerosols. Nevertheless, an additional study is needed to verify if this method is practical for pulmonary delivery.

The second study is an in-vitro study conducted at Georgia State University by Ari, Harwood, Sheard, Dailey, and Fink (2011) to evaluate the delivery of aerosol with heliox and oxygen in a pediatric ventilation model. The parameters used in this study 
were $\mathrm{V}_{\mathrm{T}} 100 \mathrm{ml}$, RR $20 \mathrm{bpm}$, and Ti $1 \mathrm{sec}$. The researchers placed a VMN (Aeroneb Solo) on the inspiratory inlet of a heated humidifier and attached a heated wire circuit to a pediatric nasal cannula (F\&P Healthcare). Then they administered $2.5 \mathrm{mg} / 3 \mathrm{ml}$ of albuterol sulfate via a pediatric $\mathrm{HFNC}$ with $100 \% \mathrm{O}_{2}$ and an $80 / 20 \%$ heliox mixture for a total of 12 runs at 3 and 6 LPM. They found that the drug deposition was equivalent between the heliox and $\mathrm{O}_{2}$ at $3 \mathrm{LPM}(11.41 \pm 1.54 \%$ and $10.65 \pm 0.51 \%$, respectively), yet was twofold greater with heliox than with $\mathrm{O}_{2}$ at 6 LPM $(5.42 \pm 0.54 \%$ and $1.95 \pm$ $0.50 \%$, respectively). The authors of this study concluded that decreasing flow rate increases albuterol delivery (by twofold) yet reduces the heliox efficiency in a HFNC pediatric model.

Both studies proved that aerosol can effectively be delivered through high flow nasal cannula using a VMN.

\section{Summary}

In conclusion, based on this review of literature, current research shows that NCPAP is a safe and effective method to be used with infants. NCPAP improves aerosol delivery in infants and could prevent the need for intubation and could minimize chronic lung injury caused by mechanical ventilation. However, few studies have compared different NCPAP devices, and the literature lacks studies that compare aerosol delivery in different NCPAP systems using an effective nebulizer device. A question remains about the best NCPAP device to be used to manage infants who requires CPAP support and the best method to deliver aerosol to those infants. Therefore, in order to improve the current practice, nebulization methods in conjunction with NCPAP devices should carefully be selected to optimize aerosol delivery while minimizing complications. Further research 
comparing different nebulizer systems combined with NCPAP systems is required in order to define the optimal aerosol delivery for spontaneously breathing infants using the combination of a NCPAP device and a nebulizer. 


\section{CHAPTER III}

\section{METHODOLOGY}

\section{Study Variables and Design}

As represented in Figure 1, the independent variables are the three CPAP generators (HFNC, B-NCPAP, and SiPAP) and the VMN positions. The dependent (outcome) variable is the aerosol drug deposition at the tracheal level of the infant lung simulator.

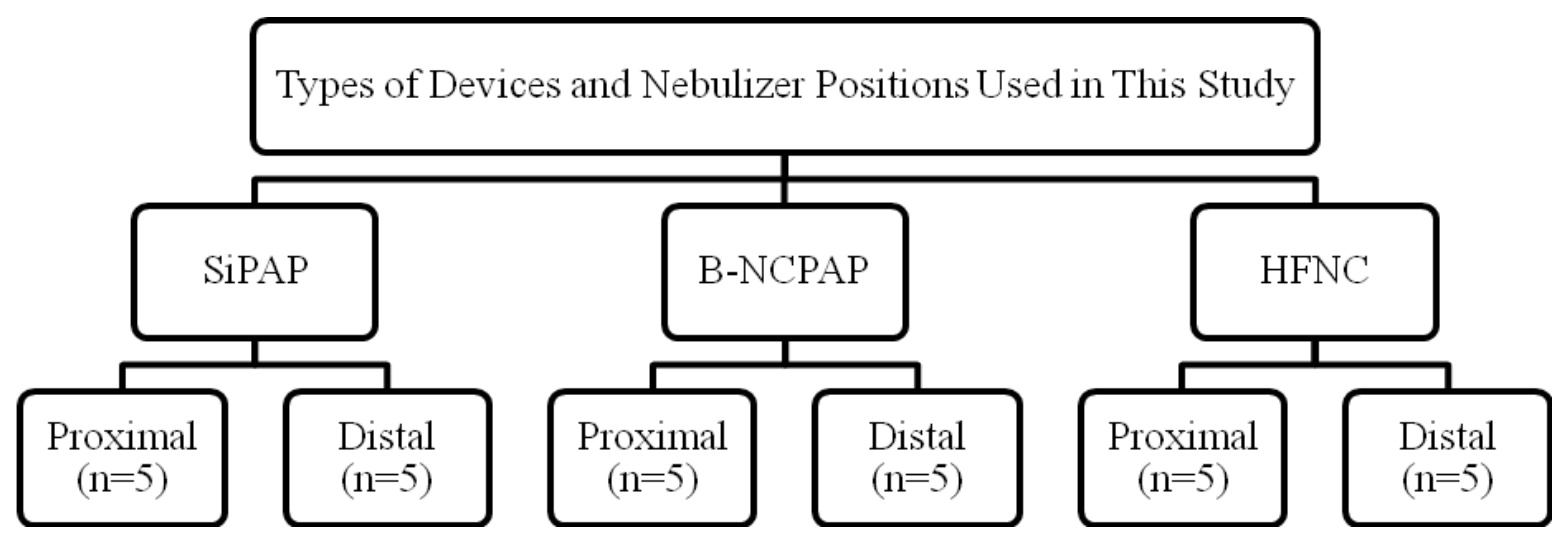

Figure 1.Organizational design of the study.

\section{Lung Model}

The in-vitro infant lung model that was used in this study consists of a breathing simulator connected to a filter (Respirgard II filter model 303, Vital signs, Inc. Totowa, NJ) distal to the trachea of an anatomic model of an upper airway of a preterm infant. The breathing parameters of the lung model were set to infant parameters of $\mathrm{V}_{\mathrm{T}} 9 \mathrm{ml}$, RR 50 
bpm, and Ti 0.5 sec. (Nikishin et al., 2011). Aerosol was administered via HFNC and CPAP through nasal prongs to the nares of the preterm infant model. As shown in Figure 2, the types of CPAP devices and their nasal prongs that were tested in this study include the following:

(1) High flow nasal cannula (HFNC)

(2) Bubble nasal CPAP (B-NCPAP), and

(3) Infant Flow "sigh" positive airway pressure (SiPAP).

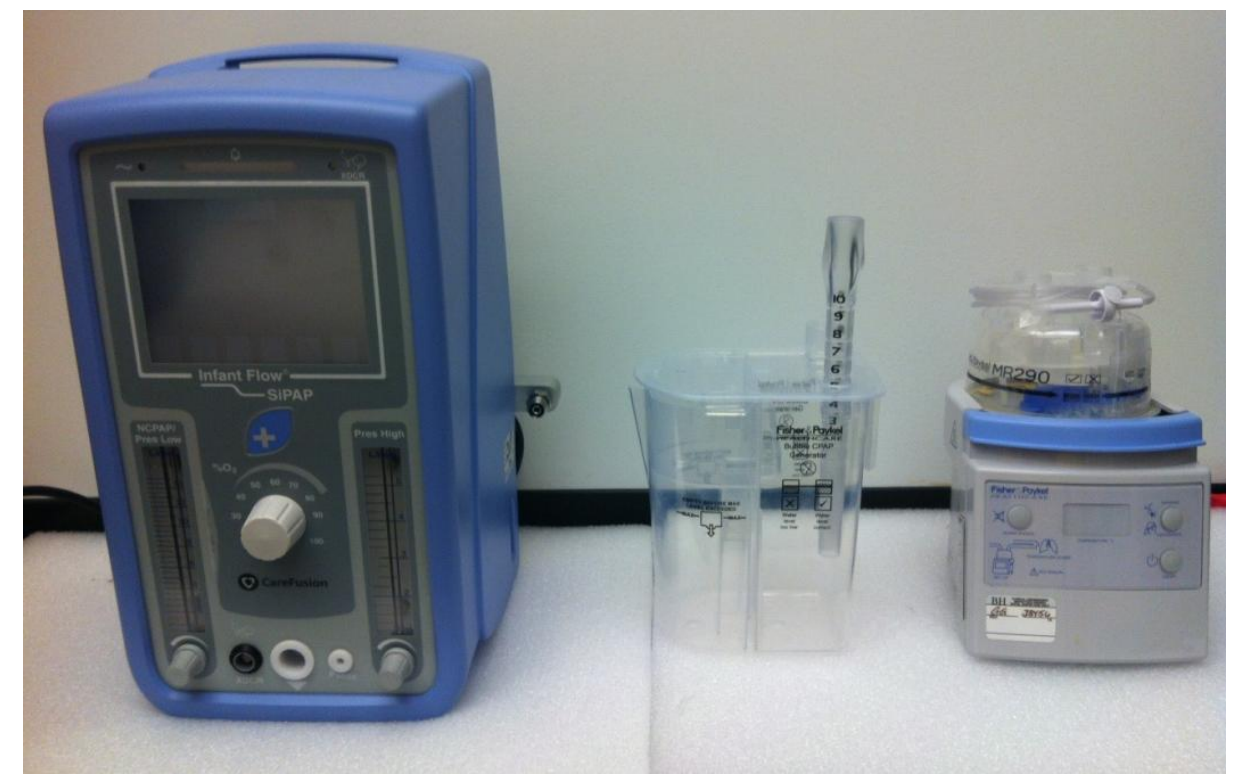
A) SiPAP system
B) Bubble CPAP system
C) HFNC system

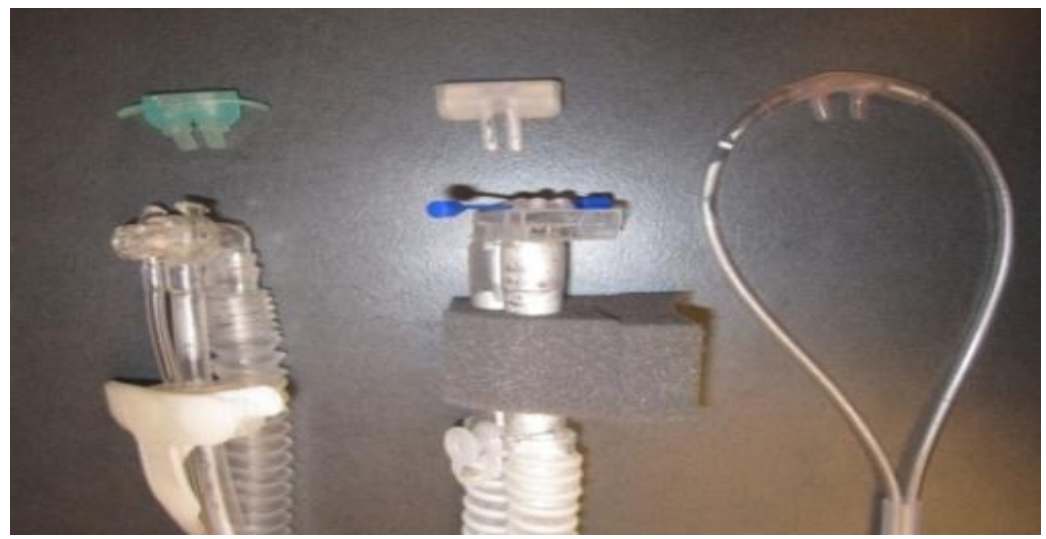
A) SiPAP
B) Bubble CPAP
C) HFNC

Figure 2.Types of CPAP systems and nasal prongs used in the study. 


\section{HFNC}

The HFNC system that was used consists of a Fisher \& Paykel Optiflow system for infants with a $10 \mathrm{~mm}$ ID heated circuit attached to an infant cannula (BC 2755, Fisher \& Paykel, Healthcare Inc. Irvine, CA) and connected to a humidifier (MR 850 heater and MR290 chamber, Fisher \& Paykel, Healthcare Inc. Irvine, CA), as shown in Figure 3. The humidifier was set to the non-invasive mode, which gives around $37{ }^{\circ} \mathrm{C}$ and $>90 \%$ relative humidity, and was filled with water and attached to a flow meter using $\mathrm{O}_{2}$ tubing. The nasal prongs of the HFNC were inserted into the infant model's nose. The pressure was measured using a flow rate of 5-6 LPM (Wilkinson et al., 2011) by a continuous recording manometer and was adjusted to deliver a pressure of $5 \mathrm{~cm} \mathrm{H}_{2} \mathrm{O}$. A flow rate of $3 \mathrm{LPM}$ generated a pressure level of $5 \mathrm{cmH}_{2} \mathrm{O}$.

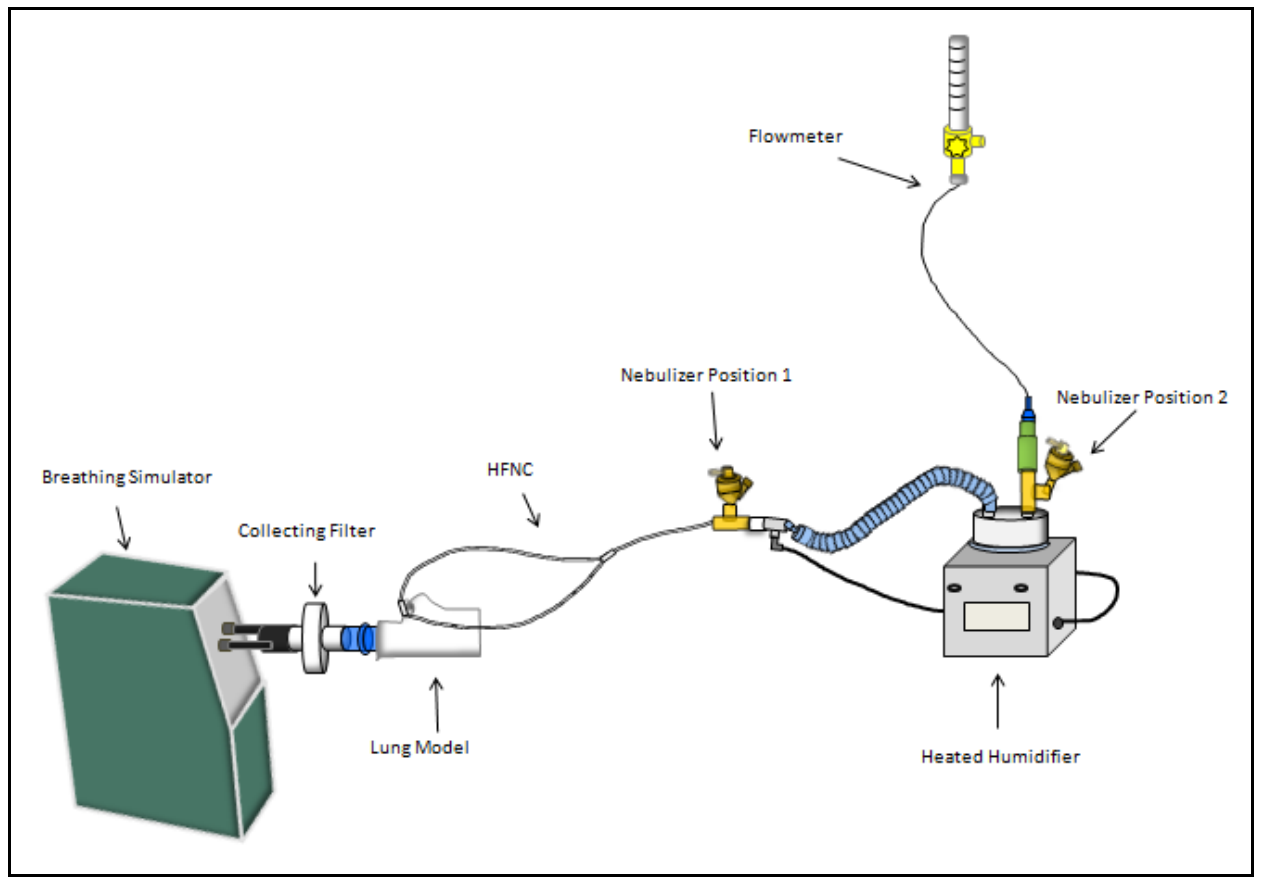

Figure 3.Experimintal set-up with HFNC. 


\section{B-NCPAP}

The lung model of the B-NCPAP system that was used in this study consists of a bubble CPAP generator; a pressure manifold (BC163-10, Fisher \& Paykel, Healthcare Inc., Irvine, CA); a humidifier (MR 850 heater and MR290 chamber, Fisher \& Paykel, Healthcare Inc., Irvine, CA);a bubble CPAP circuit; FlexiTrunk nasal tubing (BC181-08, Fisher \& Paykel, Healthcare Inc., Irvine, CA), which contains an inspiratory and an expiratory limb and nasal prongs (Figure 4). Size $3.0 \mathrm{~mm} / 2.0 \mathrm{~mm}$ nasal prongs (BC 3020-10 Fisher \& Paykel, Healthcare Inc., Irvine, CA) were used in this model. The expiratory limb was attached to a bubble CPAP device, and the inspiratory limb was attached to a heated humidifier.

The inspiratory limb of the nasal tubing was attached to the humidifier using a heated B-NCPAP circuit, and the B-NCPAP pressure manifold was connected to an air outlet (flow meter) by $\mathrm{O}_{2}$ tubing. The humidifier was set at $37{ }^{\circ} \mathrm{C}$ using the non-invasive mode and was filled with water. The bubble CPAP generator was also filled with water. The depth of the water determines the CPAP level $\left(\mathrm{P}=5 \mathrm{~cm} \mathrm{H}_{2} \mathrm{O}\right)$. The bubble CPAP generator was connected to a circuit and was attached to the expiratory limb of the FlexiTrunk nasal tubing that had the nasal prongs. The nasal prongs of the B-NCPAP were inserted into the model's nose. The intra-prong pressure also was adjusted by titrating the flow meter and was measured by a pressure manometer $(\mathrm{P}=5 \mathrm{~cm} \mathrm{H} 2 \mathrm{O})$ (Nikischin et al., 2011). In this model, a flow of 4 LPM generated a pressure level of 5 $\mathrm{cm} \mathrm{H}_{2} \mathrm{O}$. 


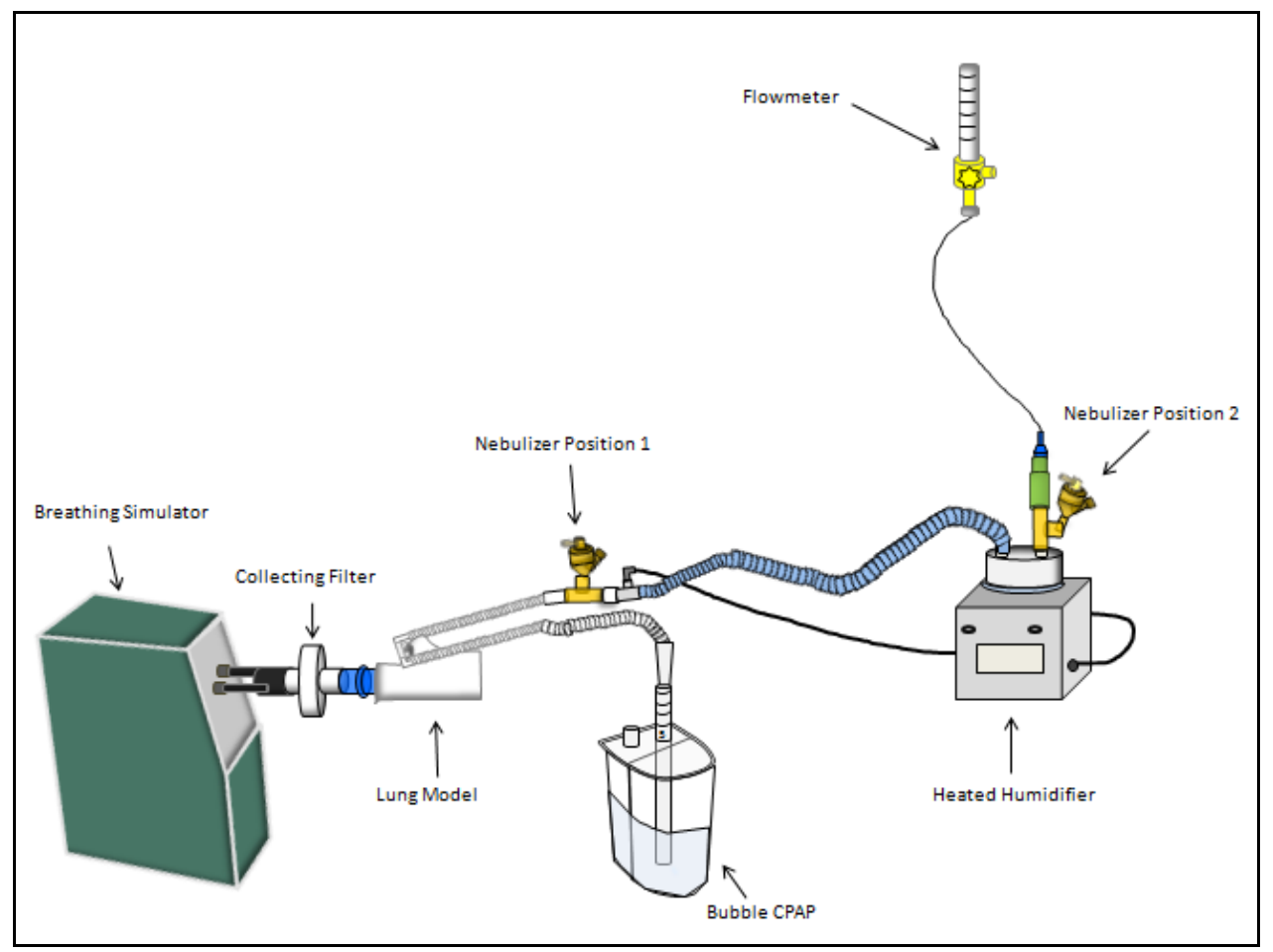

Figure 4.Experimental set-up with bubble NCPAP.

\section{SiPAP}

As shown in Figure 5, the IF-NCPAP lung model consists of a flow-derived CPAP device (Infant Flow SiPAP, CareFusion, Yorba Linda, CA) connected to a circuit attached to a humidifier by an adaptor. The humidifier was filled with water and the temperature of the humidifier was set at $37^{\circ} \mathrm{C}$ using the non-invasive mode. The humidifier also was attached to the temperature probe connected to a CPAP heated circuit using the inspiratory limb of the infant circuit (Infant Flow LP generator7772020LP, CareFusion, Yorba Linda, CA) that has the nasal prongs (777000XS, CareFusion, Yorba Linda, CA). The nasal prongs were connected to the nares of the infant lung model. The IF-CPAP flow was adjusted to generate $5 \mathrm{~cm} \mathrm{H}_{2} \mathrm{O}$ pressure; P low was set at 9LPM, and P high was set at 2 LPM (DiBlasi, 2009), and the intra-prong pressure was measured by a continuous recording pressure manometer. 


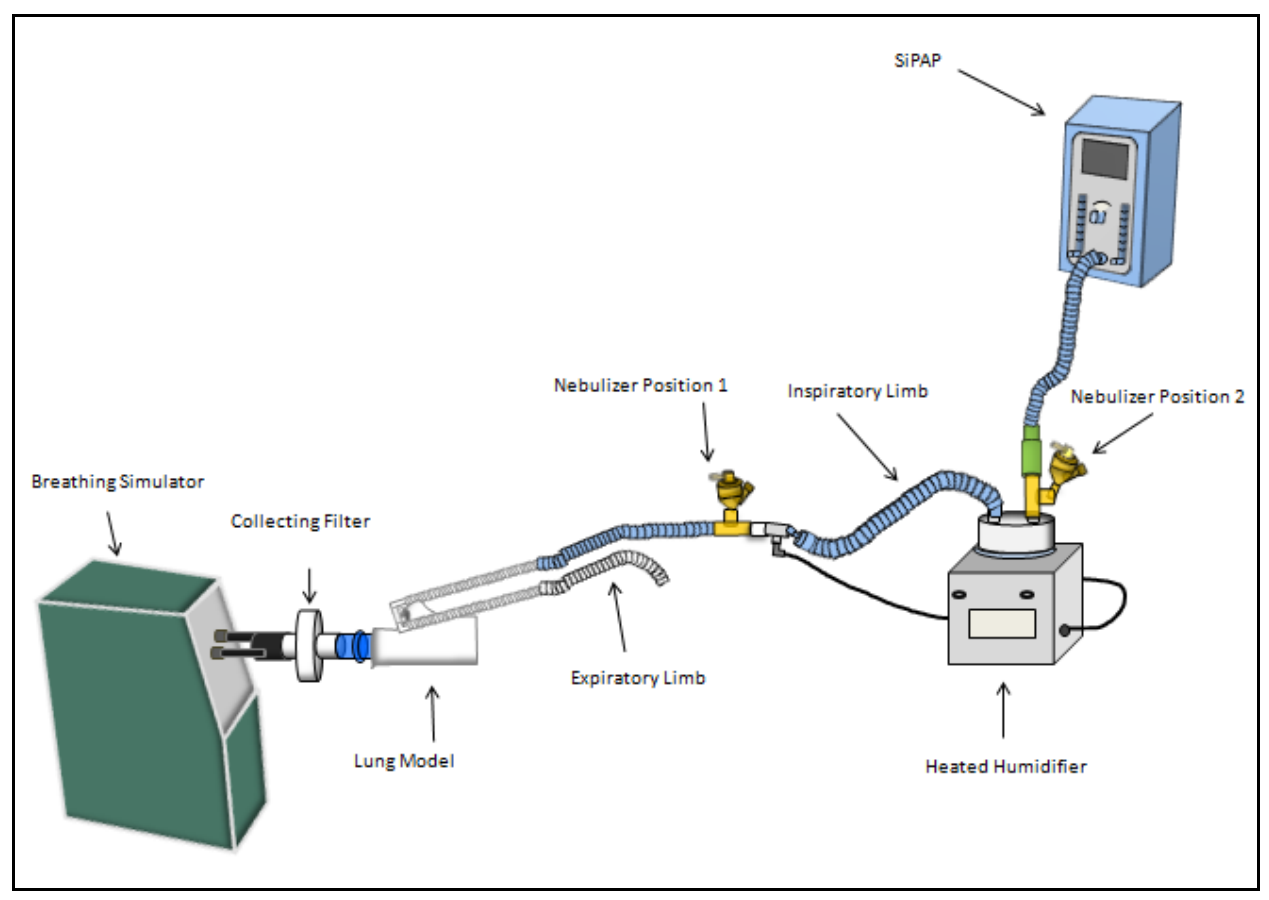

Figure 5.Experimental set-up with SiPAP.

\section{Nebulizer Type and Dose}

A vibrating mesh nebulizer (VMN) (Aeroneb Solo, Galway, Ireland) was tested in this study using a $2.5 \mathrm{mg} / 0.5 \mathrm{ml}(0.5 \%)$ unit dose of albuterol (Fink \& Kakade, 2004). The nebulizer was placed in two different positions in the inspiratory limb of the CPAP systems. The VMN was connected to each system and run until the end of nebulization.

\section{Nebulizer Position}

As shown in Figure 3, two nebulizer positions were tested in the HFNC model. For the first position (nebulizer position 1), the VMN was placed after the humidifier, between the humidifier and the nasal cannula tubing. For the second position (nebulizer position 2), the VMN was placed prior to the humidifier. In both positions, the nebulizer was run with a flow that generates similar levels of prong pressure as the two CPAP setups. 
Two positions were utilized for both the B-NCPAP system and the SiPAP system, as presented in Figures 4 and 5, respectively. In the first position, the VMN was placed proximal to the infant model, in the middle of the circuit between the humidifier and the nasal tubing. The second position was prior to the humidifier.

\section{Data Collection}

A filter was placed between the lung simulator and the trachea of the DiBlasi model. After each run was completed, the filter was detached from the circuit and soaked with $0.1 \mathrm{~N} \mathrm{HCl}$ to remove the drug. Then the albuterol drug deposition was analyzed by a spectrophotometery (Beckman Instruments, Fullerton, CA) at $276 \mathrm{~nm}$. Each condition was tested five times $(n=5)$.

\section{Data Analysis}

The percentage of aerosol deposition was measured and reported. A one-way analysis of variance (ANOVA) was used to compare the mean aerosol deposition with each system. A paired t-test was used to compare the two nebulizer positions used with the HFNC, the B-NCPAP, and the SiPAP. A $p$-value of $<0.05$ was considered to be statistically significant. 


\section{CHAPTER IV}

\section{RESULTS}

The inhaled mass and percentage of nominal dose (mean \pm SD) deposited distal to the trachea obtained with each CPAP device are represented in Table 1 and Table 2, respectively.

Table1

Mean $\pm S D$ of the Inhaled Mass Deposited Distal to the Trachea, Using HFNC, Bubble CPAP and SiPAP at Two Positions

\begin{tabular}{|l|l|l|l|l|}
\hline & HFNC & Bubble CPAP & SiPAP & P-values \\
\hline $\begin{array}{l}\text { Position 1: } \\
\text { Proximal to the patient }\end{array}$ & $22 \pm 6.5$ & $17 \pm 4.0$ & $14 \pm 4.9$ & 0.101 \\
\hline $\begin{array}{l}\text { Position 2: } \\
\text { Prior to the humidifier }\end{array}$ & $32 \pm 4.5$ & $30 \pm 6.1$ & $19 \pm 2.7$ & 0.002 \\
\hline P-values & 0.43 & 0.007 & 0.130 & \\
\hline
\end{tabular}

Table 2

Mean Lung Dose Percent \pm SD Delivered Distal to the Trachea with Each Device, Using Two Nebulizer Positions

\begin{tabular}{|l|l|l|l|l|}
\hline & HFNC & Bubble CPAP & SiPAP & P-values \\
\hline $\begin{array}{l}\text { Position 1: } \\
\text { Proximal to the patient (\%) }\end{array}$ & $0.90 \pm 0.26$ & $0.70 \pm 0.16$ & $0.59 \pm 0.19$ & 0.098 \\
\hline $\begin{array}{l}\text { Position 2: } \\
\text { Prior to the humidifier (\%) }\end{array}$ & $1.30 \pm 0.17$ & $1.24 \pm 0.24$ & $0.79 \pm 0.11$ & 0.002 \\
\hline P-values & 0.43 & 0.03 & 0.13 & \\
\hline
\end{tabular}




\section{Effect of Nebulizer Position on Aerosol Drug Deposition}

The results of this study showed that placement of the nebulizer prior to the humidifier increased aerosol deposition with all the devices tested in this study. While the trend to lower deposition across devices was not significant at Position $1(\mathrm{p}=0.098)$, differences in the mean inhaled percentage of dose delivered by each device at Position 2 were statistically significant $(p=0.002)$. Drug delivery with SiPAP was significantly less than with both HFNC ( $p=0.003)$ and bubble CPAP $(p=0.008)$ at Position 2 . No significant difference was found between HFNC and bubble CPAP on aerosol delivery at Position $2(p=0.865)$.

\section{Effect of HFNC and CPAP Systems on Aerosol Drug Delivery}

The present study demonstrates that HFNC consistently delivered more drug than bubble CPAP and SiPAP under all conditions tested. Regardless of the nebulizer position used in this study, SiPAP was the least efficient device in terms of aerosol drug delivery

in this simulated spontaneously breathing infant model. HFNC, bubble CPAP, and SiPAP were most efficient at Position 2. As distance between the nebulizer and the patient increased, aerosol delivery with each device improved. Although not significant, there was a meaningful increase on aerosol deposition with $\operatorname{SiPAP}(p=0.130)$ when the nebulizer was placed distal to the humidifier. As shown in Figure 6, the increase in the amount of inhaled drug mass obtained with bubble CPAP and HFNC at Position 2 was statistically significant ( $p=0.007$ and $p=0.43$, respectively). 


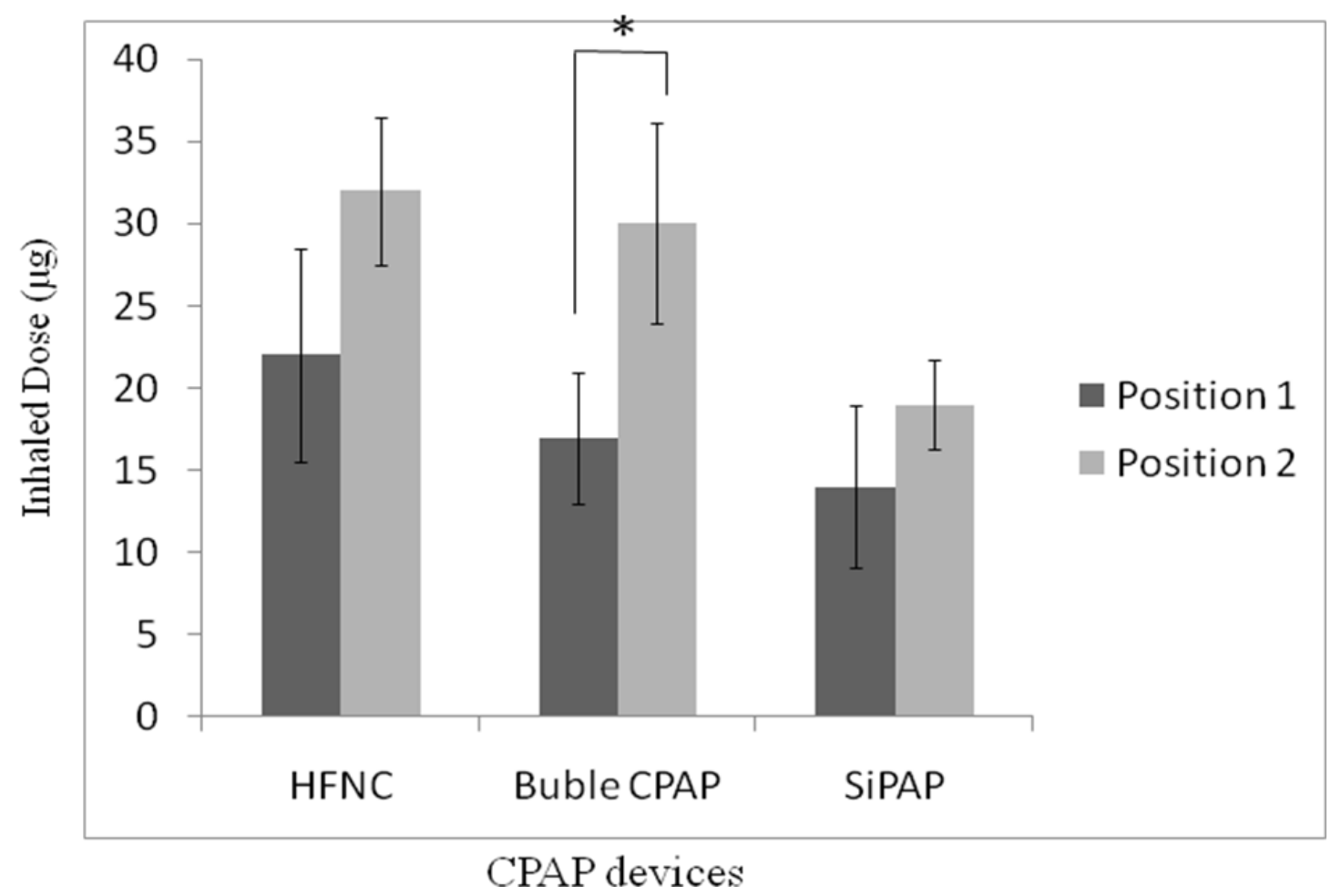

Figure 6. The mean inhaled mass $(\mu \mathrm{g}) \pm \mathrm{SD}$ of albuterol deposited distal to the trachea with HFNC, Bubble CPAP, and SiPAP using two nebulizer positions. * indicates a statistically significant difference $(\mathrm{p}<0.05)$. 


\section{CHAPTER V DISCUSSION}

HFNC, bubble CPAP, and SiPAP are commonly used CPAP delivery systems in clinical settings. These devices can also be used by clinicians to deliver aerosolized treatments via a VMN.A few studies have reported delivery of inhaled agents (i.e., iNO, surfactant) via CPAP systems. However, research indicating the efficiency of those delivery devices in aerosol drug delivery is limited and the effect of the various CPAP devices and nebulizer positions is unknown. Therefore, this study compared aerosol drug delivery using HFNC, bubble CPAP, and SiPAP and investigated the effect of nebulizer position on aerosol deposition with those devices in a simulated spontaneously breathing preterm model. This study found that HFNC was the most efficient of the three systems in terms of drug delivery. SiPAP delivered the least amount of aerosolized medication. In addition, placing the nebulizer prior to the humidifier increased aerosol deposition with all the devices tested in this study.

\section{Effect of Nebulizer Position on Aerosol Drug Deposition}

Previous research shows that the nebulizer's position on the circuit greatly affects aerosol drug delivery during mechanical ventilation and that nebulizer placement prior to the humidifier increases aerosol deposition in a mechanically ventilated pediatric lung model (Ari et al., 2010). This study also found that placing the nebulizer prior to the 
humidifier consistently delivered a higher drug mass percentage compared to placing it proximal to the nasal interface with all HFNC and CPAP systems.

Consistent with Ari et al. (2010), this study finds that placing the VMN in the circuit prior to the humidifier improves aerosol drug delivery compared to the proximal position. Ari et al. evaluated the effect of nebulizer position on aerosol drug delivery during mechanical ventilation using adult and pediatric lung models. They used a VMN to nebulize $2.5 \mathrm{mg}$ of albuterol sulfate in $3 \mathrm{ml}$ of normal saline. The VMN was placed (1) directly on the y-piece adaptor and (2) at the humidifier inlet. A heated humidifier and circuit were used in both lung models. They found that when the VMN was placed prior to the humidifier, the drug delivery increased in both lung models $(21.4 \pm 0.4 \%$ and 10.6 \pm 0.3 , respectively), compared to the proximal position $(9.7 \pm 0.6 \%$ and $8.4 \pm 0.2 \%$, respectively), with a bias flow of 5 LPM. Drug delivery was higher with the adult lung model than with the pediatric lung model.

Even though both this study and Ari et al. (2010) study similarly found that VMN is more efficient when it was placed prior to the humidifier, the present study found a lower drug deposition with both nebulizer positions. The main difference between the two studies is that Ari et al. evaluated aerosol drug delivery during mechanical ventilation with an adult and a pediatric circuit, as opposed this study's use of infant-size HFNC and CPAP systems with a smaller diameter circuit. Moreover, using a dual-chamber test lung, adult parameters used in the Ari et al. study were a $\mathrm{V}_{\mathrm{T}}$ of $500 \mathrm{ml}$, a PEEP of $5 \mathrm{~cm} \mathrm{H}_{2} \mathrm{O}$, an RR of $20 \mathrm{bpm}$, and a peak inspiratory flow of 60 LPM. The pediatric parameters they used were a $\mathrm{V}_{\mathrm{T}}$ of $100 \mathrm{ml}$, a PEEP of $5 \mathrm{~cm} \mathrm{H} \mathrm{H}_{2} \mathrm{O}$, an RR of $20 \mathrm{bpm}$, and a Ti of $1 \mathrm{sec}$. In contrast, this study used the DiBlasi lung model, and the infant parameters included a 
higher rate $(50 \mathrm{bpm})$ and a lower $\mathrm{V}_{\mathrm{T}}(9 \mathrm{ml})$. These differences in study design could account for the improved drug deposition found by Ari et al. In addition, Ari et al. used an ETT size of $8 \mathrm{~mm}$ and $5 \mathrm{~mm}$ for the adult and pediatric models, respectively; in contrast, this study used nasal prongs with smaller internal diameters. The interface's internal diameter can impact aerosol delivery. Finally, a similar VMN was used in both studies, yet Ari et al. used a higher drug dose $(3 \mathrm{ml})$ than the one used in this study $(0.5$ $\mathrm{ml})$.

\section{Effect of HFNC and CPAP Systems on Aerosol Delivery}

While research comparing aerosol drug delivery through HFNC, bubble CPAP, and SiPAP is lacking, only two studies have assessed the effectiveness of aerosol drug delivery through HFNC (Ari et al., 2011; Bhashyam et al., 2008). Moreover, only one study has compared aerosol delivery through two different CPAP systems, yet that study included V-CPAP and B-CPAP (Zweifel, 2010).

\section{HFNC}

In neonates, a flow rate of more than 1-2 LPM is considered high (Lee, Rehder, Williford, Cheifetz, \& Turner, 2013). Mosca, Colnaghi, Agosti, and Fumagalli (2012) documented a recent increase in the use of HFNC as an alternative respiratory support modality to NCPAP for preterm infants. The current literature shows that the precise mechanism of action for HFNC needs to be clarified and that the evidence supporting the superiority of HFNC over CPAP is lacking. In addition, researchers have documented inconsistent evidence supporting HFNC's safety, predominantly because of the unpredictable level of positive airway pressure delivered to premature infants (Lee et al., 2013). Despite that, HFNC is an attractive option in the treatment of infants with 
pulmonary diseases because it is easy to use, well tolerated by infants, and may decrease septum erosion with lighter pressure applied to the infant nose (Mosca et al., 2012).

This study examined the effect of HFNC on aerosol drug delivery while ensuring the same delivered CPAP level to the other two CPAP systems used in this study. Aerosol drug delivery through HFNC increased when the nebulizer position was changed from the proximal to the distal position $(0.9 \pm 0.26 \%$ and $1.3 \pm 0.17 \%$, respectively). Still, apart from the nebulizer positions tested in this study, the highest drug deposition was found in the HFNC system compared to both the bubble CPAP and the SiPAP.

Bhashyam et al. (2008) examined the aerosol deposition in HFNC, using infant, pediatric, and adult size cannulas and found that the total drug output ranged from $8.4 \pm$ $2.4 \%$ (without using a Harvard lung) to $18.6 \pm 4.0 \%$ (with a Harvard lung). Their study used the same type of mesh nebulizer as this study. Like in this study, Bhashyam et al. placed the nebulizer downstream in the inspiratory limb after the humidifier, and both studies used a flow rate of 3 LPM. Bhashyam et al. used the following infant lung parameters: RR $25 \mathrm{bpm}$ and Ti 50/50, and due to a limitation in the simulator used in their study, a pediatric $\mathrm{V}_{\mathrm{T}}$ of $150 \mathrm{ml}$ was used with the infants' cannula. Moreover, their study used around 2mCi of Technetium (Tc-99m) DTPA in $4 \mathrm{ml}$ of deionized water as their aerosolized drug, and the nebulizer ran approximately 10-13 minutes during each run. In contrast, the present study only used $0.5 \mathrm{ml}$ of albuterol, which required a shorter nebulization time. Using a higher amount of drug and a higher $\mathrm{V}_{\mathrm{T}}$ may have increased aerosol drug delivery.

Ari et al. (2011) also reported higher drug deposition compared to this study. Their results were similar to those of Bhashyam et al. (2008) when a low flow of 3 LPM 
was used. In Ari et al.'s study, the percentage of inhaled dose with $\mathrm{O}_{2}$ at 3 LPM was $10.65 \pm 0.51 \%$, and was $1.95 \pm 0.5 \%$ with $\mathrm{O}_{2}$ flow rate of $6 \mathrm{LPM}$, as compared to $1.3 \pm$ $0.17 \%$ with a flow of 3 LPM in this study. Ari et al. examined drug delivery in a pediatric HFNC at a flow rate of 3 LPM and 6 LPM, whereas this study used infant HFNC with a smaller internal diameter at a flow rate of 3 LPM. Similar to this study, Ari et al. also used an Aerogen Solo, which was placed prior to the humidifier. However, $2.5 \mathrm{mg} / 3 \mathrm{ml}$ albuterol sulfate was used to run the nebulizer as opposed to the $0.5 \mathrm{ml}$ used in this study. Furthermore, they used a breath simulator that consisted of a ventilator and a dualchamber test lung as opposed to the infant lung model with an upper airway model that was used in this study. Ari et al. noted that when the flow rate via the HFNC was increased, the inhaled dose percentage decreased, which could explain the finding in the present study of low drug deposition.

\section{B-NCPAP}

Recently, the use of bubble NCPAP has increased, particularly because B-NCPAP is safe, simple, easy to operate, inexpensive, does not require an electrical power source (DiBlasi, 2009; Kahn et al., 2008). Previous research has found that B-NCPAP may decrease the need for intubation and lower the incidence of CLD (Courtney et al., 2011; DiBlasi, 2011; Kahn et al., 2008). Moreover, B-NCPAP has become a favored device due to the perception the oscillation delivered by continuous bubbling of the device may be beneficial and may contribute to improving the gas exchange and reducing the WOB (Kahn et al., 2008; Liptsen et al., 2005). In addition, studies have shown that this continuous oscillating CPAP, delivered by bubble CPAP, may also improve lung 
recruitment without increasing the MAP and may minimize respiratory resistance (Manilal-Reddy \& Al-Jumaily, 2009).

This study examined aerosol drug delivery through bubble CPAP and found that it was the second highest after the HFNC in both the proximal and distal positions, $0.7 \%$ and $1.24 \%$, respectively.

Zweifel (2010) similarly found low drug deposition in the bubble CPAP system when the nebulizer was placed in the proximal position. Zweifel used a SAINT lung model with pediatric parameters of $\mathrm{V}_{\mathrm{T}} 100 \mathrm{ml}$, RR $30 \mathrm{bpm}$, and Ti $0.42 \mathrm{sec}$, as compared with the DiBlasi lung model used in this study with breathing parameters of $\mathrm{V}_{\mathrm{T}} 9 \mathrm{ml}$, RR $50 \mathrm{bpm}$, and Ti $0.5 \mathrm{sec}$. These differences in breathing parameters in both studies (with a lower $\mathrm{V}_{\mathrm{T}}$ and a higher $\mathrm{RR}$ ) may explain the lower deposition with the bubble CPAP found in this study. Zweifel administered $2 \mathrm{ml}$ of ventolin through a face mask to the lung model using three different nebulizers and two CPAP systems, whereas the present study used $0.5 \mathrm{ml}$ albuterol sulfate that was administered through a nasal interface using a VMN only. Zweifel found that the lung deposition through the bubble CPAP device using a different nebulizer (Aeroneb pro) in the proximal position was about $1.6 \pm 0.3 \%$, as compared to $0.7 \pm 0.16 \%$ in this study.

\section{SiPAP}

A second generation of NIV is the infant flow "sigh" positive airway pressure system (SiPAP). The main difference between the SiPAP and other IF-CPAP and NIV devices is that SiPAP permits the infant to continuously breathe at two different CPAP levels. The possible benefits of using these two pressures are reduced breathing asynchrony and WOB during both inspiration and expiration (Liptsen et al., 2005; 
Nikischin et al., 2011). Other reported advantages of these intermittent "sigh" breaths are improved alveolar recruitment and gas exchange, maintaining FRC at the end of expiration, providing airflow stimulation to avert apnea, and decreasing the need for invasive ventilation (DiBlasi, 2009, 2011). No studies investigating delivery efficiency of SiPAP in the treatment of infants with pulmonary diseases were found that could be compared to the results of this study.

\section{Clinical Implications}

This study examined aerosol drug deposition with three of the most commonly used CPAP delivery devices in clinical settings. While SiPAP is less efficient in aerosol drug delivery compared to bubble CPAP and HFNC, HFNC is the most efficient device tested in this in-vitro study.

The use of an in-line VMN has increased in practice. Using an in-line VMN with CPAP prevents the recurrent disconnection of the nasal interface to provide aerosol treatment, which prevents interrupting and losing the positive pressure required with CPAP therapy. This could minimize an infant's distress and agitation during the administration of aerosolized treatment. In addition, rather than placing the nebulizer in the proximal position, placing the nebulizer prior to the humidifier can minimize sputtering and condensation produced in the circuit. In addition, at the level of the nasal interface, this position permits the larger particles' rainout to be drained in the humidifier before entering the inspiratory limb (Ari et al., 2011). However, the effect of the rainout on the collecting filter was eliminated in this study by draining out the condensate from the circuit. 
In addition to increasing aerosol drug deposition, placing the nebulizer prior to the humidifier can prevent adding the nebulizer's weight to the nasal interface, as occurs when it is placed in the proximal position. This nebulizer position may also help in keeping the aerosol in the circuit as a reservoir during the expiratory phase, rather than allowing it to leave the system through the leak port in the expiratory limb, as occurs in the proximal position. This also could explain why higher drug deposition was found with the HFNC device compared to both the bubble CPAP device and the SiPAP device. Unlike these latter two systems, there is no exhalation port or expiratory limb in the HFNC system, which could cause aerosol particles to stay in the system during the respiratory cycle and then be directed to the nose during inspiration, as opposed to leaving the system through the exhalation port in both the bubble CPAP and SiPAP devices.

\section{Limitations of the Study}

Even though this study examined aerosol drug delivery via three CPAP delivery devices using two positions with a very effective nebulizer, only one CPAP/flow level and one set of breathing parameters of a relatively healthy premature infant lung was used. Drug delivery can be affected greatly by the size of the airway, the lung volume, RR, inspiratory flow, and the breathing pattern of the patient (Ari \& Fink, 2011). In addition, a constant set pressure and intra-prong pressure were maintained on all devices tested in this study, except the intratracheal pressure. Previous studies have shown that the actual delivered intra-airway pressure could be different from the set pressure with CPAP systems (Kahn et al., 2007). Moreover, a variety of drug delivery devices are used in clinical settings, but this study examined only one type of nebulizer. Lastly, this is an 
in-vitro study and thus does not appraise the actual clinical response of infants receiving CPAP therapy.

\section{Recommendations for Future Research}

Further studies that investigate aerosol drug delivery and measure aerosol particle size using different nebulizers and/or pMDIs, different interfaces, different breathing parameters, and different CPAP/ flow settings would guide clinicians in proper methods

to increase drug deposition in neonates. Moreover, the effect of humidification on aerosol drug delivery was not examined in this study, so conducting a similar study to measure the aerosol drug delivery with and without humidification is suggested. In addition, because sigh breaths with SiPAP improve lung recruitment, an investigation of the impact of sigh breaths during SiPAP on aerosol drug delivery is recommended. Lastly, maintaining a continuous CPAP level by avoiding circuit disconnection is crucial during CPAP therapy in order to maintain lung recruitment and decrease infants' disturbance, so further studies are needed that evaluate clinical efficiency in administering aerosol via CPAP.

\section{Conclusion}

Aerosolized medications can effectively be administered in-line with NCPAP devices tested in this study. However, it is best accomplished by HFNC. Placement of the nebulizer prior to the humidifier increased deposition with all devices tested in this study. Clinical research is warranted to identify and select the proper CPAP device, interface, and administration technique to enhance clinical efficiency of aerosol therapy. 


\section{REFERENCES}

American Association of Respiratory Care Clinical Practice Guidelines: Application of Continuous Positive Airway Pressure to Neonates via Nasal Prongs, or Nasopharyngeal Tube, or Nasal Mask—2004 Revision \& Update. (2004). Respiratory Care, 49(9), 1100-1108.

Al Sultan, H., Fink, J., Harwood, H., Sheard, M., Bryant, L., Ari, A. (2012). In-vitro comparison of aerosol drug delivery in pediatrics using pressurized metered dose inhaler, jet nebulizer, and vibrating mesh nebulizer with ambu bag. Atlanta, GA: Georgia State University.

Amirav, I., Balanov, I., Gorenberg, M., Groshar, D., \& Luder, A. (2003). Nebuliser hood compared to mask in wheezy infants: Aerosol therapy without tears! Archives of Disease in Childhood, 88(8), 719-723

Ari, A., Atalay, O. T., Harwood, R., Sheard, M. M., Aljamhan, E. A., \& Fink, J. B. (2010). Influence of nebulizer type, position, and bias flow on aerosol drug delivery in simulated pediatric and adult lung models during mechanical ventilation. Respiratory Care, 55(7), 845-851.

Ari, A., \& Fink, J. B. (2011). Guidelines for aerosol devices in infants, children and adults: Which to choose, why and how to achieve effective aerosol therapy. Expert Review of Respiratory Medicine, 5(4), 561-572. 
Ari, A., Harwood, R., Sheard, M., Dailey, P., \& Fink, J. B. (2011). In vitro comparison of heliox and oxygen in aerosol delivery using pediatric high flow nasal cannula. Pediatric Pulmonology, 46(8), 795-801.

Ari A., Hess D., Myers T., \& Rau J. L. (2009). A guide to aerosol delivery devices for respiratory therapists. Dallas, TX: American Association for Respiratory Care.

Ari, A., \& Restrepo, R. D. (2012). Aerosol delivery device selection for spontaneously breathing patients: 2012. Respiratory Care, 57(4), 613-626.

Bahman-Bijari, B., Malekiyan, A., Niknafs, P., \& Baneshi, M. (2011). Bubble-CPAP vs. Ventilatory-CPAP in preterm infants with respiratory distress. Iranian Journal of Pediatrics, 21(2), 151-158.

Bhashyam, A. R., Wolf, M. T., Marcinkowski, A. L., Saville, A., Thomas, K., Carcillo, J. A., \& Corcoran, T. E. (2008). Aerosol delivery through nasal cannulas: An in vitro study. Journal of Aerosol Medicine and Pulmonary Drug Delivery, 21(2), 181-188.

Bober, K., Swietlinski, J., Zejda, J., Kornacka, K., Pawlik, D., Behrendt, J., ... Bachman, T. (2012). A multicenter randomized controlled trial comparing effectiveness of two nasal continuous positive airway pressure devices in very-low-birth-weight infants. Pediatric Critical Care Medicine, 13(2), 191-196.

Campbell, D., Shah, P., Shah, V., \& Kelly, E. (2006). Nasal continuous positive airway pressure from high flow cannula versus infant flow for preterm infants. Journal of Perinatology, 26(9), 546-549. 
Chua, H. L., Collis, G. G., Newbury, A. M., Chan, K., Bower, G. D., Sly, P. D., \& Le, S. P. N. (1994). The influence of age on aerosol deposition in children with cystic fibrosis. The European Respiratory Journal, 7(12), 2185-2191.

Courtney, S., \& Barrington, K. (2007). Continuous positive airway pressure and noninvasive ventilation. Clinics in Perinatology, 34(1), 73-92.

Courtney, S., Kahn, D., Singh, R., \& Habib, R. (2011). Bubble and ventilator-derived nasal continuous positive airway pressure in premature infants: Work of breathing and gas exchange. Journal of Perinatology, 31(1), 44-50.

De Paoli, A., Davis, P., Faber, B., \& Morley, C. (2008). Devices and pressure sources for administration of nasal continuous positive airway pressure (NCPAP) in preterm neonates. Cochrane Database of Systematic Reviews, (1), 1-51.

Dhand, R. (2007). Inhalation therapy in invasive and noninvasive mechanical ventilation. Current Opinion in Critical Care, 13(1), 27-38.

DiBlasi, R. (2009). Nasal continuous positive airway pressure (CPAP) for the respiratory care of the newborn infant. Respiratory Care, 54(9), 1209-1235.

DiBlasi, R. M. (2011). Neonatal noninvasive ventilation techniques: Do we really need to intubate? Respiratory Care, 56(9), 1273-1297.

Dubus, J. C., Vecellio, L., De Monte, M., Fink, J. B., Grimbert, D., Montharu, J.,... Diot, P. (2005). Aerosol deposition in neonatal ventilation. Pediatric Research, 58(1), $10-14$.

Farney, K., Kuehne, B., \& Gibson, L. (2010). Evaluation of systemic circuit particle deposition using the Aerogen micropump aerosol generator with a variable flow NCPAP system. Respiratory Care. 
Finer, N. N., Merritt, T. A., Job, L., Bernstein, G., Mazela, J., \& Segal, R. (2010). An open label, pilot study of aerosurf combined with nCPAP to prevent RDS in preterm neonates. Journal of Aerosol Medicine and Pulmonary Drug Delivery, 23(5), 303-309.

Fink, J., \& Kakade, P. (2004). Improving aerosol delivery to infants during nasal CPAP: An in vitro model [Abstract]. Respiratory Care. Retrieved from 2004 Open Forum Abstracts from Respiratory Care database: http://www.rcjournal.com/abstracts/2004/?id=OF-04-264\%20Fink

Gregory, G. A., Kitterman, J. A., Phibbs, R. H., Tooley, W. H., \& Hamilton, W. K. (1971). Treatment of the idiopathic respiratory-distress syndrome with continuous positive airway pressure. New England Journal of Medicine, 284(24), 1333-1340.

Kahn, D. J., Courtney, S. E., Steele, A. M., \&Habib, R. H. (2007). Unpredictability of delivered bubble nasal continuous positive airway pressure: role of bias flow magnitude and nares-prong air leaks. Pediatric Research, 62(3), 343-347.

Kahn, D., Habib, R., \& Courtney, S. (2008). Effects of flow amplitudes on intraprong pressures during bubble versus ventilator-generated nasal continuous positive airway pressure in premature infants. Pediatrics, 122(5), 1009-1013.

Kattwinkel, J., Fleming, D., Cha, C. C., Fanaroff, A. A., \&Klaus, M. H. (1973). A device for administration of continuous positive airway pressure by the nasal route. Pediatrics, 52(1), 131-134.

Koti, J., Murki, S., Gaddam, P., Reddy, A., \& Reddy, M. D. (2010). Bubble CPAP for respiratory distress syndrome in preterm infants. Indian Pediatrics, 47(2), 139143. 
Kubicka, Z., Limauro, J., \& Darnall, R. (2008). Heated, humidified high flow nasal cannula therapy: Yet another way to deliver continuous positive airway pressure? Pediatrics, 121(1), 82-88.

Lee, J., Rehder, K., Williford, L., Cheifetz, I., \& Turner, D. (2013). Use of high flow nasal cannula in critically ill infants, children, and adults: A critical review of the literature. Intensive Care Medicine, 39(2), 247-257.

Liptsen, E., Aghai, Z. H., Pyon, K. H., Saslow, J. G., Nakhla, T., Long, J.,... Courtney, S. E. (2005). Work of breathing during nasal continuous positive airway pressure in preterm infants: a comparison of bubble vs variable-flow devices. Journal of Perinatology, 25(7), 453-458.

Malloy, R., Glynn, B., Pullar, S., Delaney, K., \&Greenspan, J. (2003). Bubble CPAP versus infant flow CPAP in neonates. Respiratory Care,48(11), 1074

Manilal-Reddy, P., \& Al-Jumaily, A. (2009).Understanding the use of continuous oscillating positive airway pressure (bubble CPAP) to treat neonatal respiratory disease: An engineering approach. Journal of Medical Engineering \& Technology, 33(3), 214-222.

Mosca, F., Colnaghi, M., Agosti, M., \&Fumagalli, M. (2012). High-flow nasal cannula: Transient fashion or new method of non-invasive ventilatory assistance? Journal of Maternal-Fetal \& Neonatal Medicine, 25(54), 2568-2569.

Nikischin, W., Petridis, M., Noeske, J., Spengler, D., \& von Bismarck, P. (2011). Effect on work of breathing of different continuous positive airway pressure devices evaluated in a premature neonatal lung model. Pediatric Critical Care Medicine, 12(6), 376-382. 
Restrepo, R., Dickson, S., Rau, J., \& Gardenhire, D. (2006). An investigation of nebulized bronchodilator delivery using a pediatric lung model of spontaneous breathing. Respiratory Care, 51(1), 56-61.

Roberts, C., Badgery-Parker, T., Algert, C., Bowen, J., \& Nassar, N. (2011). Trends in use of neonatal CPAP: A population-based study. BMC Pediatrics, 11, 89.

Rojas, M. A., Lozano, J. M., Rojas, M. X., Rondon, M. A., Charry, L., Laughon, M.,... Jaramillo, M. L. (2009). Very early surfactant without mandatory ventilation in premature infants treated with early continuous positive airway pressure: A randomized, controlled trial. Pediatrics, 123(1), 137-142.

Schüepp, K. G., Jauernig, J., Janssens, H. M., Tiddens, H. A., Straub, D. A., Stangl, R., ... Wildhaber, J. (2005). In vitro determination of the optimal particle size for nebulized aerosol delivery to infants. Journal of Aerosol Medicine, 18(2), 225235.

Shoemaker, M. T., Pierce, M. R., Yoder, B. A., \&DiGeronimo, R. J. (2007). High flow nasal cannula versus nasal CPAP for neonatal respiratory disease: a retrospective study. Journal of Perinatology, 27(2), 85-91.

Smedsaas-Löfvenberg, A., Nilsson, K., Moa, G., \& Axelsson, I. (1999). Nebulization of drugs in a nasal CPAP system. Acta Paediatrica, 88(1), 89-92.

Spence, K. L., Murphy, D., Kilian, C., McGonigle, R., \& Kilani, R. A. (2007). High-flow nasal cannula as a device to provide continuous positive airway pressure in infants. Journal of Perinatology, 27(12), 772-775.

Sreenan, C., Lemke, R. P., Osiovich, H., \& Hudson-Mason, A. (2001). High-flow nasal cannulae in the management of apnea of prematurity: a comparison with 
conventional nasal continuous positive airway pressure. Pediatrics, 107(5), 10811083.

Tagare, A., Kadam, S., Vaidya, U., Pandit, A., \& Patole, S. (2009). A pilot study of comparison of BCPAP vs. VCPAP in preterm infants with early onset respiratory distress. Journal of Tropical Pediatrics, 56(3), 191-194.

Urs, P., Khan, F., \& Maiya, P. (2009). Bubble CPAP — A primary respiratory support for respiratory distress syndrome in newborns. Indian Pediatrics, 46(5), 409-411.

Volsko, T. A., Fedor, K., Amadei, J., \& Chatburn, R. L. (2011). High Flow through a nasal cannula and CPAP effect in a simulated infant model. Respiratory Care, 56(12), 1893-1900.

Welzing, L., Bagci, S., Abramian, A., Bartmann, P., Berg, C., \& Mueller, A. (2011). CPAP combined with inhaled nitric oxide for treatment of lung hypoplasia and persistent foetal circulation due to prolonged PPROM. Early Human Development, 87(1), 17-20.

Wilkinson, D., Andersen, C., \& Holberton, J. (2008). Pharyngeal pressure with high-flow nasal cannulae in premature infants. Journal of Perinatology, 28(1), 42-47.

Wilkinson, D., Andersen, C., O'Donnell, C., \& De Paoli, A. (2011). High flow nasal cannula for respiratory support in preterm infants. Cochrane Database of Systematic Reviews, (5).

Zweifel, N. S. (2010). In vitro aerosol delivery from nebulizers through two set ups of continuous positive airway pressure $(C P A P)$ ventilation using an infant model. Zurich, Switzerland: University of Zurich. 